Copyright

by

Phillip Gene Doerner III

2010 
The Thesis Committee for Phillip Gene Doerner III Certifies that this is the approved version of the following thesis:

Chromium Chloride Increases Insulin-Stimulated Glucose Uptake In The Perfused Rat Hindlimb

\section{APPROVED BY}

SUPERVISING COMMITTEE:

Supervisor:

John L. Ivy

Roger P. Farrar 


\title{
Chromium Chloride Increases Insulin-Stimulated Glucose Uptake In The Perfused
} Rat Hindlimb

by

\section{Phillip Gene Doerner III, B.A.}

\author{
Thesis \\ Presented to the Faculty of the Graduate School of \\ The University of Texas at Austin \\ in Partial Fulfillment \\ of the Requirements \\ for the Degree of
}

Master of Science in Kinesiology

The University of Texas at Austin

December 2010 


\section{Acknowledgements}

First I would like to thank Jeff for his assistance in all facets of this study. Whether it was coming in early to make solutions for the perfusions, choosing our daily music selection, or reading over numerous drafts of my papers, Jeff helped me every step of the way. Second, thank you to Henry for helping with western blotting and data collection. Without him, we may still be working. Also, thank you to Ding for his help and encouragement throughout this process. Finally, I would like to thank Dr. John Ivy for his guidance, advice and support during my time at The University of Texas.

-Phillip Doerner

December 2, 2010 


\begin{abstract}
Chromium Chloride Increases Insulin-Stimulated Glucose Uptake In The Perfused Rat Hindlimb
\end{abstract}

Phillip Gene Doerner III, M.S. Kin.

The University of Texas at Austin, 2010

Supervisor: John L. Ivy

Chromium has been reported to increase glucose clearance in insulin resistant and diabetic populations. Skeletal muscle is the tissue primarily responsible for glucose clearance. We therefore tested the effect of chromium chloride $\left(\mathrm{CrCl}_{3}\right)$ on skeletal muscle glucose uptake both in the absence and presence of a submaximal level of insulin via the rat hindlimb perfusion technique. $0.096 \mu \mathrm{M} \mathrm{CrCl}_{3}$ was used with and without 200 $\mu \mathrm{U} / \mathrm{ml}$ insulin. Our testing showed that insulin significantly increased $\left[\mathrm{H}^{3}\right]-2$ deoxyglucose (2-DG) uptake in both the gastrocnemius and quadriceps muscles. Additionally, the combination of $\mathrm{CrCl}_{3}$ and insulin (Cr-sIns) led to greater amounts of 2DG uptake than insulin alone (sIns) in both the gastrocnemius (Cr-sIns 6.49 \pm 0.75 $\mu \mathrm{mol} / \mathrm{g} / \mathrm{h}$, sIns $4.83 \pm 0.42 \mu \mathrm{mol} / \mathrm{g} / \mathrm{h}$ ) and quadriceps (Cr-sIns $6.74 \pm 0.62 \mu \mathrm{mol} / \mathrm{g} / \mathrm{h}, \mathrm{sIns}$ $4.54 \pm 0.43 \mu \mathrm{mol} / \mathrm{g} / \mathrm{h}$ ). However, $\mathrm{CrCl}_{3}$ without insulin $(\mathrm{Cr})$ had no affect on 2-DG uptake above basal (Bas) in both the gastrocnemius ( $\mathrm{Cr} 1.45 \pm 0.14 \mu \mathrm{mol} / \mathrm{g} / \mathrm{h}$, Bas $1.61 \pm 30$ $\mu \mathrm{mol} / \mathrm{g} / \mathrm{h}$ ) and the quadriceps (Cr $1.35 \pm 0.15 \mu \mathrm{mol} / \mathrm{g} / \mathrm{h}$, Bas $1.27 \pm 0.13 \mu \mathrm{mol} / \mathrm{g} / \mathrm{h}$ ). It has been speculated that chromium works to increase glucose uptake by increasing insulin 
signaling. To examine this, we used western blotting analysis to test both Akt and AS160 phosphorylation in the mixed gastrocnemius. We found that insulin increased Akt and AS160 phosphorylation, but chromium had no affect on Akt (Cr-sIns $25 \% \pm 2 \%$, sIns $22 \% \pm 4 \%$ ) or AS160 (Cr-sIns 35\% ${ }_{5} \%$, sIns $36 \% \pm 4 \%$ ) phosphorylation in the absence or presence of insulin. Our results suggest that supplementation with $\mathrm{CrCl}_{3}$ can lead to an increase in glucose uptake in skeletal muscle, but only in the presence of insulin. However, this effect of $\mathrm{CrCl}_{3}$ does not appear to be a result of enhanced insulin signaling.

\section{Key words: Insulin Signaling, Trace Minerals, Skeletal Muscle}




\section{Table of Contents}

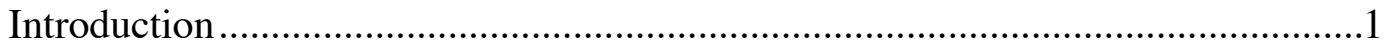

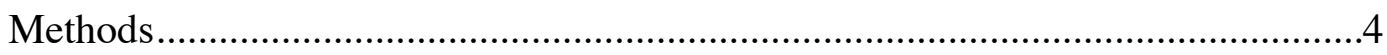

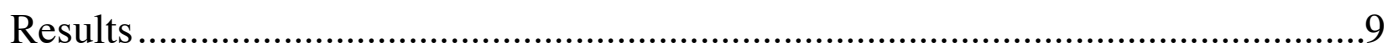

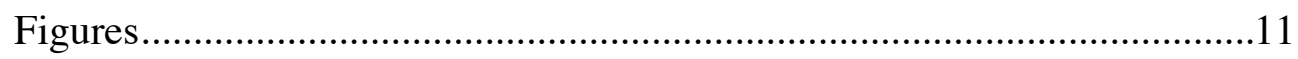

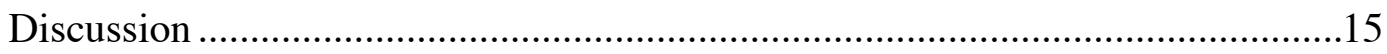

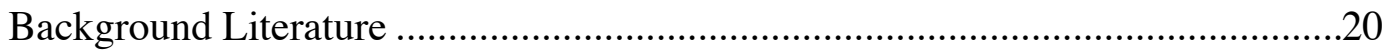

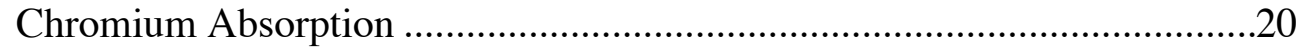

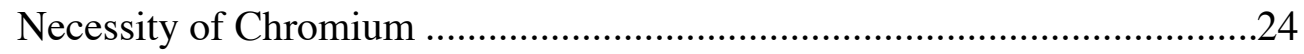

Chromium and Glucose Intolerance ...................................................22

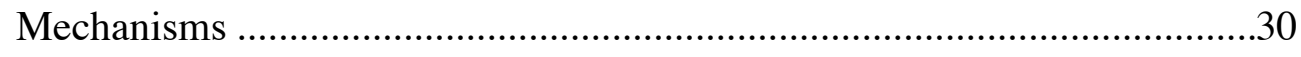

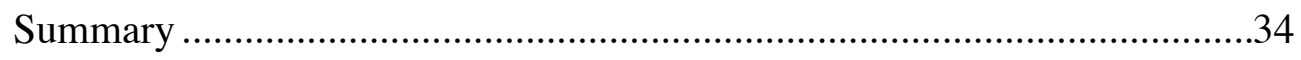

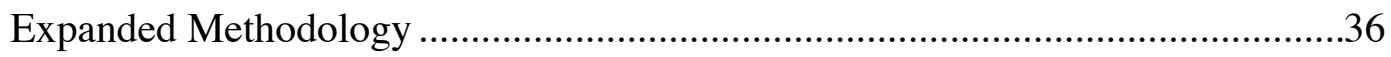

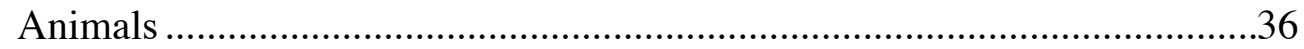

Experimental Design and Surgery …...................................................36

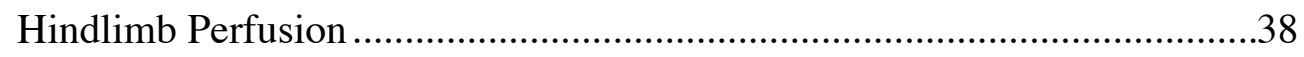

Tissue Preparation for Glucose Uptake ...................................................39

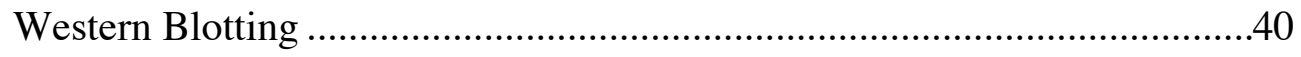

Appendix A - Muscle Homogenization ........................................................42

Appendix B - Krebs Buffer ....................................................................43

Appendix C - Wet Transfer Buffer ..........................................................45

Appendix D - Protein Assay (Bradford) ....................................................46

Appendix E - Individual Muscle Data.........................................................47

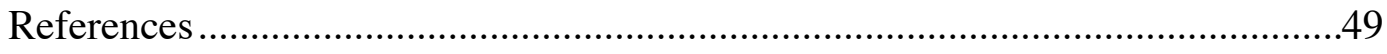

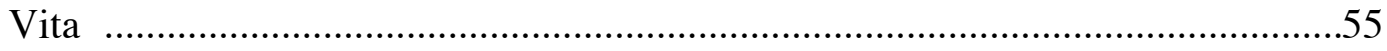




\section{Introduction}

Diabetes mellitus is one of the largest concerns currently facing human health. There are two forms of diabetes, type 1 and type 2. While type 1 diabetes is characterized by an autoimmune attack on the insulin producing $\beta$-cells of the pancreas, type 2 diabetes is the result of lifestyle choices and cases of type 2 diabetes are on the rise (75). Obesity, as a result of diet and inactivity, has long been thought to lead to type 2 diabetes $(4,15)$. Insulin resistance characterizes type 2 diabetes, resulting in impaired glucose tolerance. More specifically, type 2 diabetes results in the peripheral muscles' inability to react to released insulin and disposal of blood glucose (23).

Insulin activates glucose transport into skeletal muscle by eliciting the translocation of GLUT4 from intracellular areas to the plasma membrane. Two of the most important signaling proteins involved in this process are Akt and AS160. Akt, also known as PKB, is an insulin controlled protein kinase that is involved in multiple processes in the body (42). AS160 is a $160 \mathrm{kDa}$ substrate of Akt and is one of the final signaling proteins involved in GLUT4 translocation (21). In the basal state, AS160 acts as a brake on a Rab-GDP protein that is thought to control GLUT4 translocation. Once AS160 is phosphorylated, the Rab-GDP protein is allowed to become active as a RabGTP, allowing GLUT4 to translocate to the plasma membrane $(58,62)$.

Multiple treatment methods have been put into practice to combat type 2 diabetes. In some cases, simple augmentation of diet and exercise has shown to be successful in treating type 2 diabetes $(1,17)$. For some patients, medication such as Metformin and Sulfonylurea have been shown to be successful in treating the symptoms of type 2 
diabetes $(33,64)$. One method that has been proposed as a combatant for type 2 diabetes is supplementation with chromium $(52,57)$.

Chromium, while fairly unstudied, has been known about for some time.

Chromium was first mentioned as possibly being involved with glucose uptake in 1959 (59), and since then has generated some controversy. While many researchers believe that chromium is necessary for human glucose control, others doubt its efficacy (66). Still, chromium has been deemed an essential nutrient needed in human nutrition and used as a supplement to increase lean weight in farm animals as well as being one of the highest sold supplements for humans $(2,49)$.

One of the earliest studies showing the necessity of chromium in humans involved a patient who was receiving total parenteral nutrition (38). The patient began showing signs of insulin resistance, needing large amounts of insulin to dispose of glucose. After increasing the amount of insulin given and seeing no improvements, chromium was added, reversing the effects of the insulin resistance and allowing for a decrease in the amount of insulin provided. Additionally, multiple studies in populations of patients with insulin resistance have shown that chromium supplementation leads to improved glucose tolerance $(7,12,65)$. However, additional studies have shown that chromium supplementation has no effect on glucose uptake in patients with normal glucose tolerance $(5,70)$. It has been demonstrated that the absorption rate of chromium is extremely low $(10,47)$. This low rate of absorption from the gut and into the muscles may in part lead to some of the discrepancies seen in studies investigating chromium. 
While it has been shown repeatedly that chromium ingestion in diabetic populations results in improved glucose metabolism, the mechanism by which chromium affects glucose disposal is unknown. Much of the research into how chromium augments glucose metabolism has been completed recently, and is still inconclusive. The majority of studies have shown that chromium increases insulin signaling by increasing phosphorylation of the insulin receptor, leading to an increase in Akt activation $(27,67$, 68). However, other studies have determined that augmentation of the plasma membrane is responsible for the increase in glucose uptake $(22,50)$.

The purpose of this study was to investigate the effects of chromium supplementation on skeletal muscle glucose uptake in the presence and absence of a submaximally-stimulating concentration of insulin. By performing perfusions with and without insulin, we were able to determine if chromium directly affects glucose uptake, or simply augments insulin action. 


\section{Methods}

Animals. All research and handling procedures were approved by the Institutional Animal Care and Use Committee (IACUC) of The University of Texas at Austin. Twenty-eight male Sprague Dawley rats (Harlan, Houston, TX) were obtained for testing. Rats were received at 7 weeks of age. The rats were housed 2 to a cage and fed a standard laboratory chow (ProLab RMH 1800, Labdiet, Brentwood, MO) and provided with water ad libitum. The room housing the animals was kept at $21{ }^{0} \mathrm{C}$ with an artificial 12 hour/12 hour light-dark cycle. Upon arrival, rats were randomly separated by weight into 1 of 4 groups: chromium with sub maximal insulin (Cr-sIns, n=8), sub maximal insulin (sIns, $\mathrm{n}=9)$, chromium without insulin $(\mathrm{Cr}, \mathrm{n}=6)$, and basal (Bas, $\mathrm{n}=5)$.

Experimental Design and Surgery. In order to determine glucose uptake in the rat skeletal muscle, the hindlimb perfusion technique was utilized. Hindlimb perfusion has been shown to be both a viable and popular experimental model to examine glucose metabolism under physiological conditions $(18,71)$.

Rats were subjected to testing at 9 weeks of age. After a 12-hour fast, rats were anesthetized with an intraperitoneal injection of pentobarbital sodium $(6.5 \mathrm{mg} / 100 \mathrm{~g}$ body weight). The surgical technique and the perfusion apparatus were similar to that previously described $(37,56)$. Briefly, the purpose of the surgery was to tie off vessels in the abdominal cavity and the left limb while exposing the inferior vena cava and descending aorta. Cannulation of the right iliac artery and inferior vena cava could be 
performed, thus allowing the perfusate to flow from the arterial catheter, to the circulatory bed of the right hindlimb, and finally out through the venous catheter.

Perfusate solutions. All solutions for the perfusion procedure were prepared in $6 \%$ BSA. $2 \mathrm{mM}$ Na-pyruvate was added to the $6 \%$ BSA for the basal washout solution. The Bas perfusate solution contained $2 \mathrm{mM}$ Na-pyruvate, $6 \mathrm{mM}$ glucose, $2 \mathrm{mM}$ mannitol, 0.2 $\mu \mathrm{Ci} / \mathrm{ml} \mathrm{H}^{3}-2$ deoxyglucose and $0.15 \mu \mathrm{Ci} / \mathrm{ml} \mathrm{C}^{14}$-Sucrose. The washout solution for the Cr group contained $2 \mathrm{mM}$ Na-pyruvate and $0.096 \mu \mathrm{M} \mathrm{CrCl}_{3}$. The $\mathrm{Cr}$ perfusate solution was composed of $2 \mathrm{mM}$ Na-pyruvate, $0.096 \mu \mathrm{M} \mathrm{CrCl}_{3}, 6 \mathrm{mM}$ glucose, $2 \mathrm{mM}$ mannitol, $0.2 \mu \mathrm{Ci} / \mathrm{ml} \mathrm{H}^{3}-2$ deoxyglucose and $0.15 \mu \mathrm{Ci} / \mathrm{ml} \mathrm{C}^{14}$-Sucrose. The washout solution for the sIns group was made of $2 \mathrm{mM}$ Na-pyruvate and $200 \mu \mathrm{U} / \mathrm{ml}$ insulin. The perfusate solution contained $2 \mathrm{mM}$ Na-pyruvate, $200 \mu \mathrm{U} / \mathrm{ml}$ insulin, $6 \mathrm{mM}$ glucose, $2 \mathrm{mM}$ mannitol, $0.2 \mu \mathrm{Ci} / \mathrm{ml} \mathrm{H}^{3}-2$ deoxyglucose and $0.15 \mu \mathrm{Ci} / \mathrm{ml} \mathrm{C}^{14}$-Sucrose. The $\mathrm{Cr}$-sIns washout solution was made of $2 \mathrm{mM}$ Na-pyruvate, $200 \mu \mathrm{U} / \mathrm{ml}$ insulin and $0.096 \mu \mathrm{M}$ $\mathrm{CrCl}_{3}$. The perfusate solution for the Cr-sIns group contained $2 \mathrm{mM}$ Na-pyruvate, 200 $\mu \mathrm{U} / \mathrm{ml}$ insulin, $0.096 \mu \mathrm{M} \mathrm{CrCl}_{3}, 6 \mathrm{mM}$ glucose, $2 \mathrm{mM}$ mannitol, $0.2 \mu \mathrm{Ci} / \mathrm{ml} \mathrm{H}^{3}-2$ deoxyglucose and $0.15 \mu \mathrm{Ci} / \mathrm{ml} \mathrm{C}^{14}$-Sucrose.

Hindlimb perfusion The cannulated rat was placed in line with the perfusion system. The perfusate was continuously mixed on a magnetic stir plate. The perfusate first passed through a roller pump, which was calibrated at $6 \mathrm{ml} / \mathrm{min}$ for the washout and 3 $\mathrm{ml} / \mathrm{min}$ for the perfusate. The perfusate then passed through approximately 3 meters of 
Silastic tubing (Dow Corning, Midland, MI) contained in an artificial lung, which was gassed with a mixture of $95 \% \mathrm{O}_{2}$ and $5 \% \mathrm{CO}_{2}$. Next, the perfusate passed through a heated water jacket maintained at $37^{\circ} \mathrm{C}$, and then through a bubble trap before entering the hindlimb of the rat via the arterial catheter. After circulating through the right hindlimb the perfusate exited through the venous catheter and was collected in a beaker on ice for later analysis.

The hindlimb was allowed to stabilize during a 10 minute washout period. After the washout period, the rat was perfused for 25 minutes with the nonrecirculating perfusate solution. Aliquots of the arterial samples were taken in order to determine the specific activity of the isotopes to help determine the skeletal muscle glucose uptake. After the perfusion was performed, the right gastrocnemius and quadriceps were removed, freeze clamped in liquid nitrogen and stored at $-80^{\circ} \mathrm{C}$ for later analysis.

Skeletal muscle glucose uptake. Pieces of frozen gastrocnemius and quadriceps were cut and weighed. The pieces were digested in $1 \mathrm{ml}$ of $1 \mathrm{M} \mathrm{KOH}$ for 20 minutes at $60^{\circ} \mathrm{C}$. The digested muscle was neutralized with $1 \mathrm{ml}$ of $1 \mathrm{M} \mathrm{HCL}$ before $300 \mu \mathrm{l}$ of the mixture was added to $6 \mathrm{ml}$ BioSafe II scintillation cocktail (Research Products International, Mt. Prospect, IL). An LS-6500 Multi Purpose Scintillation Counter (Beckman Coulter, Inc., Brea CA) was used to count duplicate samples of ${ }^{3} \mathrm{H}$ and ${ }^{14} \mathrm{C}$. Uptake of 2-DG in the muscle was calculated as the difference between total muscle 2-DG and extracellular 2DG. Extracellular space was determined from the from tissue concentration of $\left[{ }^{14} \mathrm{C}\right]-$ Sucrose, since the sucrose cannot cross the plasma membrane (34-36). 
Tissue processing for signaling protein immunoblotting. Frozen gastrocnemious muscle was pulverized in a mortar and pestle in liquid nitrogen. Homogenization buffer $(20 \mathrm{mM}$ Hepes, 2 mM EGTA, 50 mM NaF, 100 mM KCl, 0.2 mM EDTA, 50 mM glycerophosphate, $1 \mathrm{mM}$ DTT, $0.1 \mathrm{mM}$ PMSF, $1 \mathrm{mM}$ Benzamidine, $0.5 \mathrm{mM} \mathrm{Na}$ Vanadate) was added to the chilled mortar. After pulverization, the powdered muscle was added to a glass tissue grinder (Corning Stirrer Type RZR1, Wiarton, Ont. Canada) with additional homogenization buffer to dilute the sample at a dilution factor of 9:1. The samples were thoroughly mixed in the grinder for 10 seconds 3 times each. The homogenate was then centrifuged at $4^{0} \mathrm{C}$ for 10 minutes at $14,000 \mathrm{x}$. Following the centrifugation, the protein concentration of the supernatant was analyzed using the Bradford method (19) (Bio-Rad Laboratories, Hercules, CA). The supernatant was then aliquoted into multiple vials and stored at $-80{ }^{0} \mathrm{C}$ until analyzed.

Antibodies for signaling protein immunoblotting. The antibodies used were specific for the proteins examined; phosphorylated AS160 (Thr642 \#4288S), phosphorylated Akt(Thr308, \#4056S), total AS160 (Anti-AS160 Rab-GAP Rabbit antiserum) and total Akt (Akt Rabbit Ab). A horseradish peroxidase (HRP)-conjugated secondary anti-rabbit IgG was used for a secondary antibody. All antibodies were purchased from Cell Signaling Technology (Danvers, MA) except total AS160, which was purchased from Upstate (Temecula, CA). 
Signaling protein immunoblotting. Equal amounts of muscle protein $(40 \mu \mathrm{g})$ were separated by SDS-PAGE using $10 \%$ polyacrylamide gels and then transferred on to a nitrocellulose membrane (Millipore Corp, Bedford, MA) using a wet transfer unit (BioRad Laboratories, Hercules, CA). The membranes were blocked before being incubated overnight with primary antibody. The following day the membranes were incubated for 90 minutes with secondary antibodies and then visualized with enhanced chemiluminescence (ECL, Perkin Elmer, Boston, MA). After exposure of phosphorylated proteins, membranes were placed in a stripping buffer ( $\mathrm{pH}$ 6.7, 7.5g Tris Base, 20g SDS, $7 \mathrm{ml} \beta$-me) for one hour. Membranes were then washed 2 times for 5 minutes and then probed for total protein. Protein blots were quantified by a ChmDoc ECL detection system and Quantitiy One software (both Bio-Rad, Hercules, CA). Akt and AS160 phosphorylation was analyzed as a percentage of total Akt and AS160.

Statistics. Data from the glucose uptake and protein phosphorylation was subjected to a two-way analysis of variance (two-way ANOVA) with chromium and insulin being the two independent variables, and upon verification of significant interaction, means were compared using Fisher's Least Significance Difference post hoc test. A level of $\mathrm{P}<0.05$ was deemed statistically significant. All values are expressed as means \pm SEM. 


\section{Results}

Animal characteristics. 28 male Sprague Dawley rats were used in this study. Rats were aged 9 weeks before undergoing testing and were randomized by weight into separate groups (Cr-sIns 295.89 \pm 5 g, sIns $296.38 \pm 3$ g, Cr $291 \pm 5$ g, Bas $296 \pm 3$ g).

Chromium increases glucose uptake in insulin-stimulated skeletal muscle. Glucose uptake for the gastrocnemius is shown in Fig. 1, and for the quadriceps is shown in Fig. 2. Insulin had a significant effect on skeletal glucose uptake in both the gastrocnemius and quadriceps, leading to a 3.77 and a 4.26 fold increase, respectively. Chromium alone had no affect. However, there was significant interaction between chromium and insulin. Post hoc analysis indicated the chromium and insulin together increased glucose uptake compared to insulin alone in the gastrocnemius by $42 \%$ (Cr-sIns $6.86 \pm 0.74 \mu \mathrm{mol} / \mathrm{g} / \mathrm{h}$, sIns $4.83 \pm 0.42 \mu \mathrm{mol} / \mathrm{g} / \mathrm{h}$ ) and in the quadriceps by $47 \%$ (Cr-sIns $6.67 \pm 0.70 \mu \mathrm{mol} / \mathrm{g} / \mathrm{h}$, sIns $4.54 \pm 0.43 \mu \mathrm{mol} / \mathrm{g} / \mathrm{h})$. When chromium was perfused in the absence of insulin it had no effect on skeletal muscle glucose uptake.

Chromium has no affect on Akt phosphorylation. Phosphorylation of Akt at $\mathrm{Thr}^{308}$ in the gastrocnemius was analyzed using Western blots. Results are shown as a percentage of the total Akt protein content. Insulin perfusion resulted in an increase in Akt phosphorylation, while chromium had no affect on Akt phosphorylation in the absence of insulin $(\mathrm{Cr} 4 \% \pm 1 \%$, Bas $4 \% \pm 1 \%)$ or in the presence of insulin (Cr-sIns $23 \% \pm 2 \%$, sIns $22 \% \pm 4 \%)$.

Chromium has no affect on AS160 phosphorylation. Phosphorylation of AS160 at $\mathrm{Thr}^{642}$ in the gastrocnemius was analyzed using Western blots. Results are shown as a 
percentage of the total protein content. Insulin perfusion led to a 2.71 fold increase in AS160 phosphorylation. Chromium supplementation had no affect on AS160

phosphorylation in the absence of insulin $(\mathrm{Cr} 14 \% \pm 3 \%$, Bas $12 \% \pm 3 \%)$ or in the presence of insulin (Cr-sIns 37\% $\pm 5 \%$, sIns 36\% $\pm 4 \%$ ). 


\section{FIGURES}

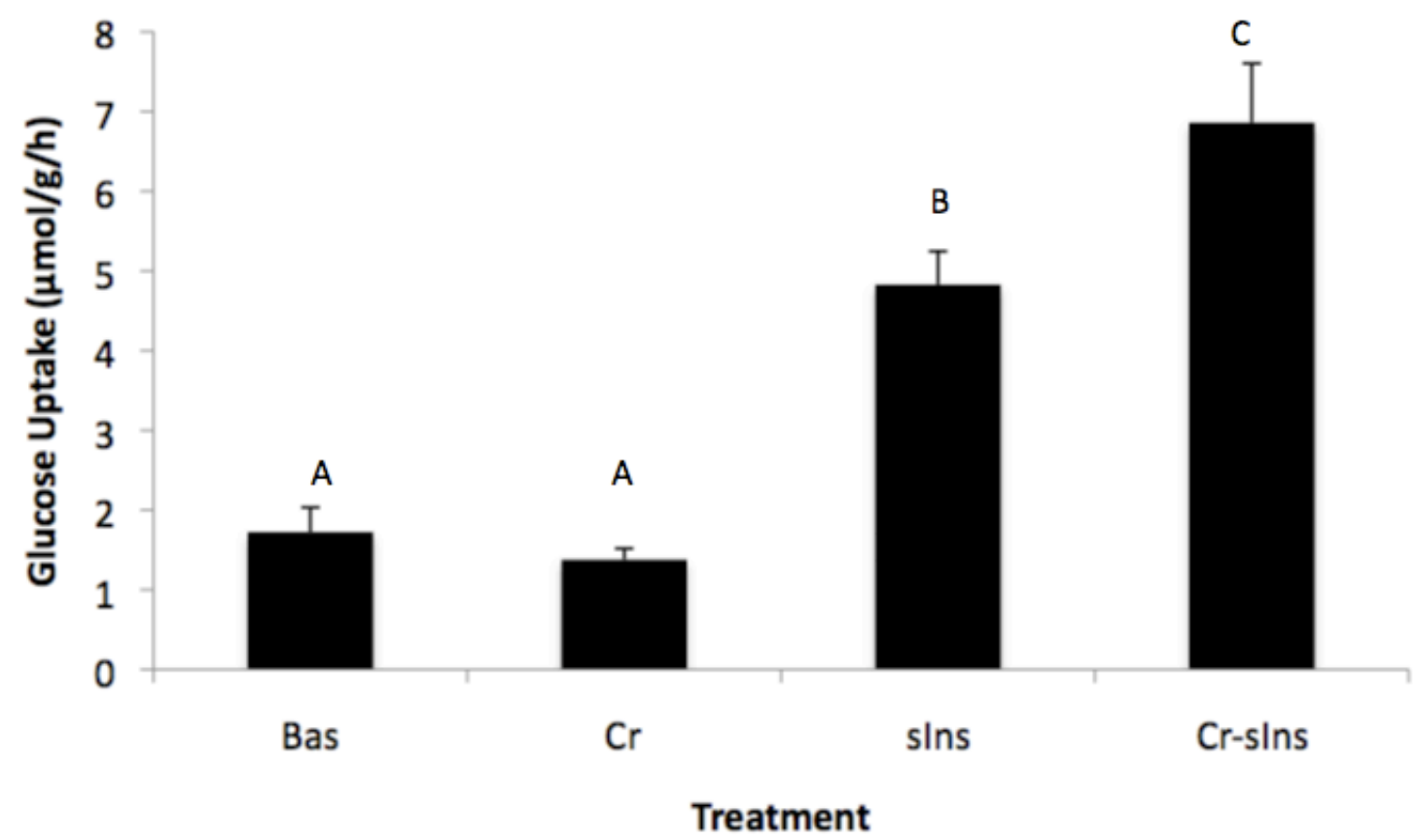

Figure 1. The effect of chromium on glucose uptake in the gastrocnemuis with and without submaximal insulin. The right hindlimb was prepared for hindlimb perfusion and washed-out for 10 minutes, followed by 25 minutes of perfusion with a perfusate containing neither chromium nor insulin (Bas), chromium with no insulin $(\mathrm{Cr})$, submaximal insulin without chromium (sIns) or chromium with submaximal insulin (CrsIns). Values are means $\pm \mathrm{SEM}$ in $\mu \mathrm{mol} / \mathrm{g} / \mathrm{h}$. Means with difference letters are significantly different from each other $(\mathrm{P}<0.05)$. 


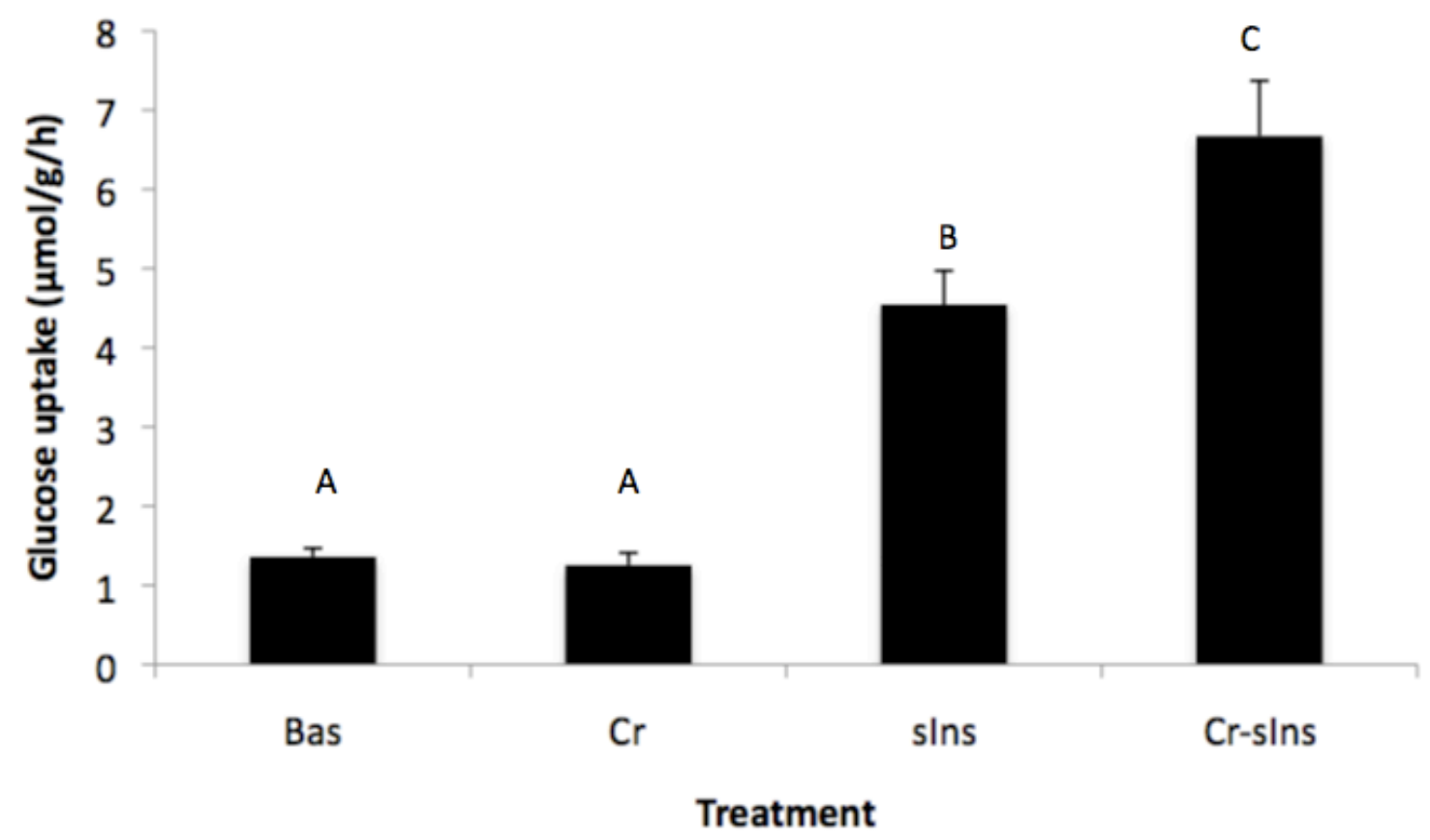

Figure 2. The effect of chromium on glucose uptake in the quadriceps with and without submaximal insulin. The right hindlimb was prepared for hindlimb perfusion and washed-out for 10 minutes, followed by 25 minutes of perfusion with a perfusate containing neither chromium nor insulin (Bas), chromium with no insulin (Cr), submaximal insulin without chromium (sIns) or chromium with submaximal insulin $(\mathrm{Cr}-$ sIns). Values are means $\pm \mathrm{SEM}$ in $\mu \mathrm{mol} / \mathrm{g} / \mathrm{h}$. Means with difference letters are significantly different from each other $(\mathrm{P}<0.05)$. 


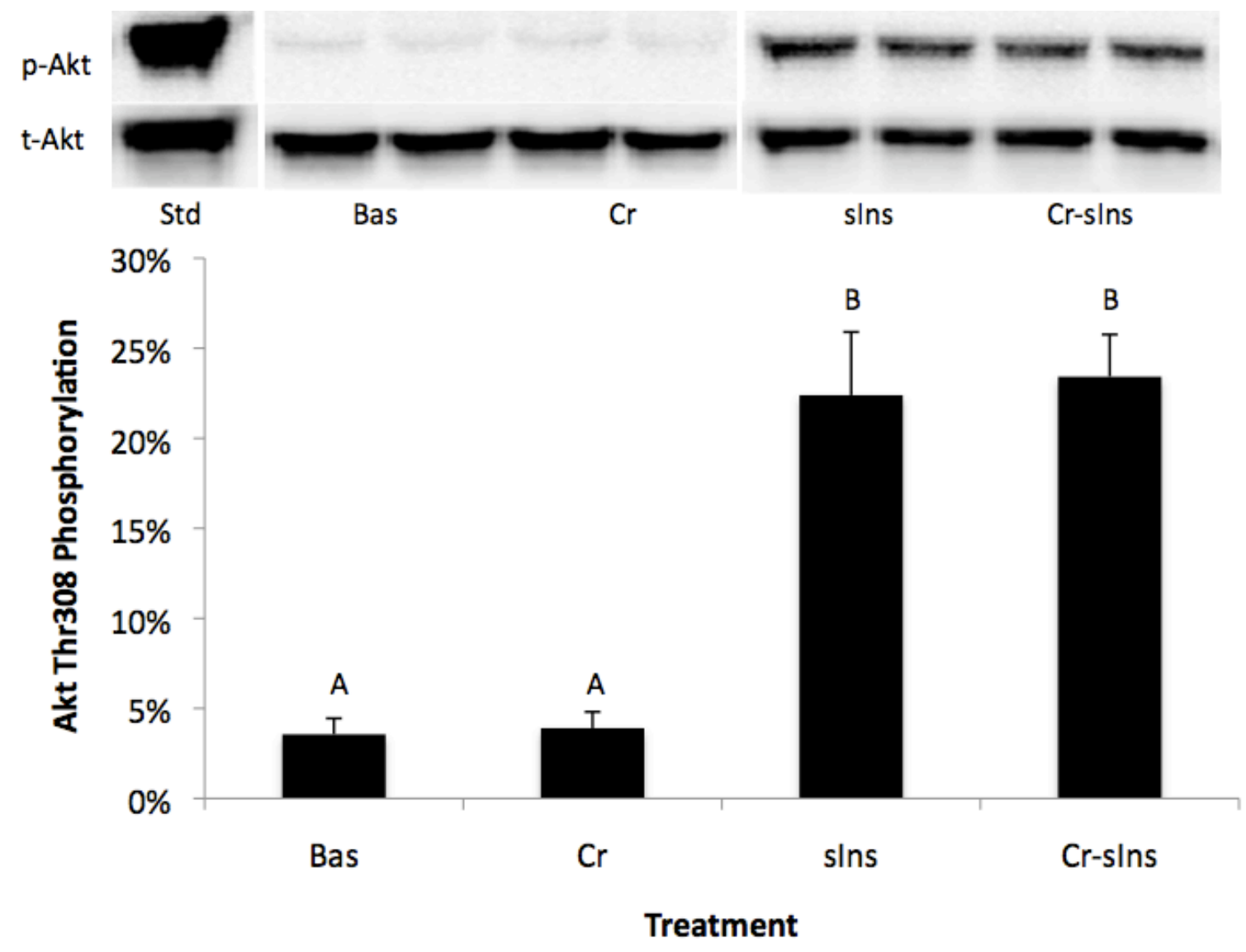

Figure 3. The effect of chromium on Akt $\mathrm{Thr}^{308}$ phosphorylation with and without submaximal insulin. Data are expressed as a fraction of total Akt content. The right hindlimb was prepared for hindlimb perfusion and washed-out for 10 minutes, followed by 25 minutes of perfusion with a perfusate containing neither chromium nor insulin (Bas), chromium with no insulin (Cr), submaximal insulin without chromium (sIns) or chromium with submaximal insulin (Cr-sIns). Values are means \pm SEM. Means with difference letters are significantly different from each other $(\mathrm{P}<0.05)$. 


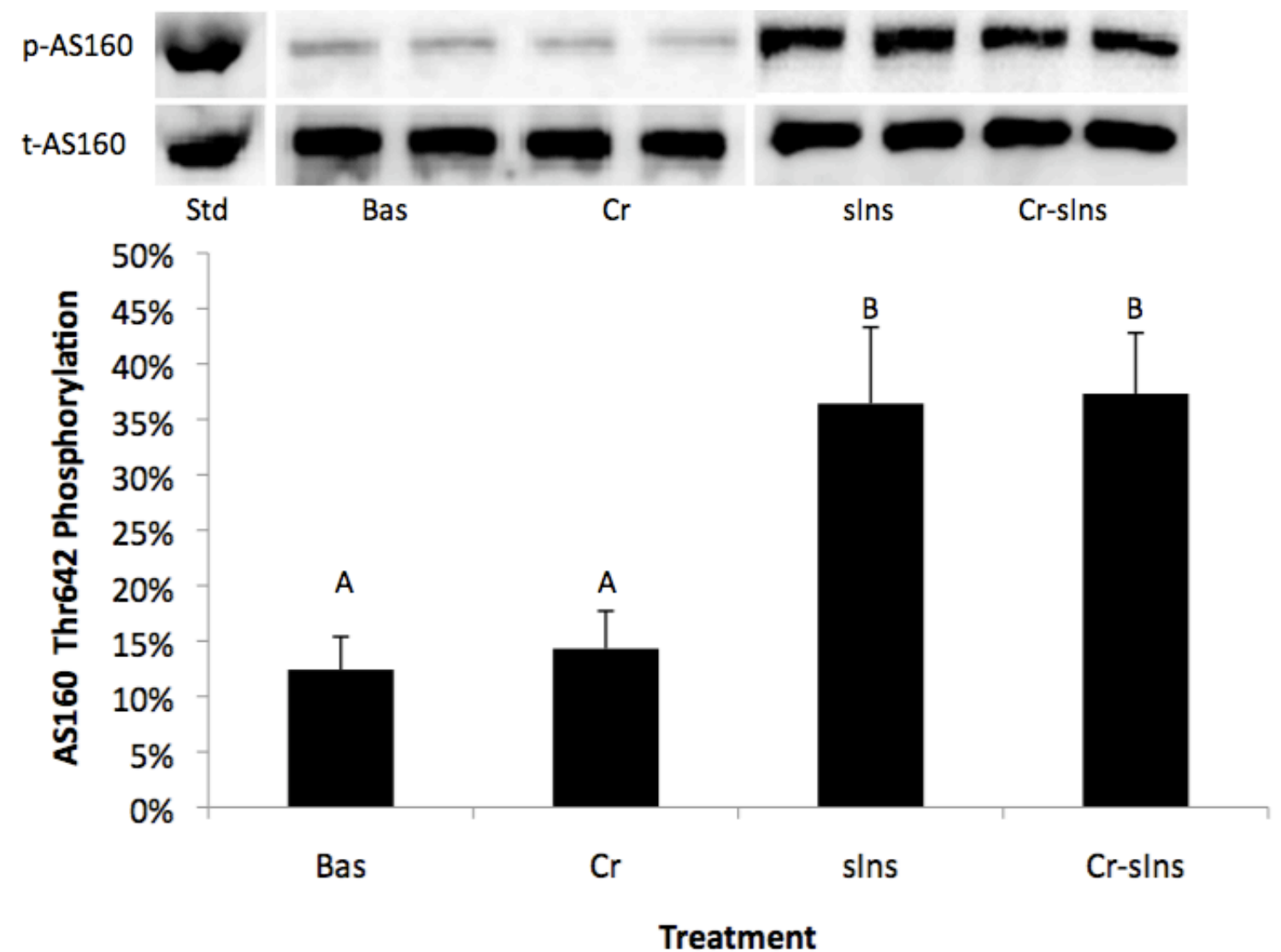

Figure 4. The effect of chromium on AS160 $\mathrm{Thr}^{642}$ phosphorylation with and without submaximal insulin. Data are expressed as a fraction of total As160 content. The right hindlimb was prepared for hindlimb perfusion and washed-out for 10 minutes, followed by 25 minutes of perfusion with a perfusate containing neither chromium nor insulin (Bas), chromium with no insulin (Cr), submaximal insulin without chromium (sIns) or chromium with submaximal insulin (Cr-sIns). Values are means \pm SEM. Means with difference letters are significantly different from each other $(\mathrm{P}<0.05)$. 


\section{Discussion}

The present study has two key findings. First, it was shown that perfusion with chromium chloride can lead to an increase in insulin-stimulated glucose uptake in normal skeletal muscle. In the presence of a submaximally stimulating insulin concentration, chromium increased glucose uptake in the gastrocnemius and quadriceps muscles by $42 \%$ and $47 \%$, respectively. Additionally, it was shown that chromium perfusion only worked in the presence of insulin. This suggests that chromium works as a cofactor of insulin, enhancing its action.

Many studies have shown that chromium supplementation increases glucose metabolism in insulin resistant populations $(16,38,51)$. However, when healthy subjects have been examined, it has been shown that chromium has no effect on glucose metabolism $(14,70)$. A meta-analysis performed by Althuis et al. (5) examined the effects of chromium supplementation on glucose response. The authors determined that chromium supplementation had no effect on glucose response in non-diabetic subjects. A definite explanation as to why chromium seems ineffective in healthy populations has yet to be determined.

Studies in both humans $(10,39)$ and animals $(41,46)$ have shown that chromium absorption is very low. Specifically, Oberleas et al. (47) investigated the transit time of chromium through the gut in rats. The study showed that the transit time of chromium is short, leading to lower levels of uptake in the gut. With chromium absorption in the gut being low, chromium levels in the blood will in turn be low $(8,41)$. These results suggest 
that chromium levels in the blood, thus the amounts of chromium transported to the muscle, are very low. Additionally, a study by Anderson and Kozlovsky (10) as well as a study by Offenbacher et al. (48) analyzed chromium absorption in humans. Anderson and Kozlovsky (10) found that in subjects consuming $10 \mu \mathrm{g}$ of chromium, $2 \%$ was absorbed, while in subjects consuming $40 \mu \mathrm{g}$ of chromium, only $0.5 \%$ was absorbed. Offenbacher et al. (48) found that in two subjects, daily chromium intake was 36.9 and $36.7 \mu \mathrm{g}$ of chromium a day and absorption was only 0.9 and $0.5 \mu \mathrm{g}$ of chromium, respectively.

Taking these studies together, it can be inferred that while necessary, the amount of chromium needed in the body is very low. As a result of low absorption in the gut, only small amounts of chromium reach the muscles. By utilizing the hindlimb perfusion technique, the gut was bypassed and the muscle was exposed to high levels of chromium. The result of this high level of exposure led to increased insulin-stimulated skeletal muscle glucose uptake. Oral supplementation does not seem to present a problem in a diabetic population. Even though chromium absorption is low, apparently very little is needed to increase glucose uptake in otherwise unhealthy and impaired muscles. However, blood chromium levels needed to increase glucose uptake in insulin resistant muscle appears to be inadequate to positively influence non-insulin resistant muscle. Still, it is possible that the exposure of healthy muscle to high levels of chromium could have a similar effect as to that seen in insulin resistant muscle.

In addition to glucose uptake, the effect of the perfusion of chromium on insulin signaling was analyzed in this study. The majority of studies have suggested that 
chromium increases glucose uptake by augmenting the insulin-signaling pathway via increasing activity of the insulin receptor kinase $(7,25,68)$. This in turn would lead to an increase in downstream signaling, such as increased Akt phosphorylation. Yang et al. (72) analyzed chromium and Akt phosphorylation in mouse 3T3-L1 adipocytes. The authors found that the addition of chromium to insulin-stimulated cell cultures resulted in Akt phosphorylation above that of insulin alone. Additionally, Dong et al. (27) showed chromium increases Akt phosphorylation in chronically supplemented mice. Insulin resistant mice underwent 9 weeks of supplementation with $\mathrm{Cr}(\mathrm{D}-\mathrm{phe})_{3}$. When chromium supplemented mice were given an intraperitoneal injection of insulin, Akt phosphorylation levels of insulin resistant mice equaled that of healthy control mice. Our results showed chromium had no effect on either insulin-stimulated or noninsulinstimulated Akt phosphorylation. We also found that chromium had no affect on AS160 phosphorylation under these conditions. This would be expected, as we saw no increase in Akt phosphorylation in the presence or absence of insulin.

Since we found in the present study that glucose uptake increased without an increase in insulin signaling, there must be some other mechanism responsible. It has been reported that chromium supplementation affects glucose uptake through augmentation of the fluidity of the plasma membrane $(22,29,50)$. It is postulated that GLUT4 has an increased affinity for areas of the plasma membrane that exhibit greater fluidity, leading to an increased incorporation of GLUT4 into the plasma membrane (53). Pattar et al. (50) found that chromium increased membrane fluidity in mouse 3T3-L1 adipocytes. Evans and Bowman (29) found that the addition of chromium led to an 
increase in plasma membrane fluidity in rat myoblasts. Additionally, the authors found that the increase in plasma membrane fluidity led to an increase in glucose uptake. Chen et al. (22) examined the effect chromium had on both membrane fluidity and glucose uptake in 3T3-L1 adipocytes cultured in a high glucose medium. The results suggested that chromium increased membrane fluidity and insulin-stimulated glucose uptake. Membrane fluidity was not analyzed in our study. However, as we saw an increase in glucose uptake without alteration of the insulin-signaling pathway, this could be a viable explanation as to the mechanism of action of chromium.

It has been shown that chromium does not act alone but only in the presence of insulin $(22,51)$. This has been confirmed in the present study. Chen et al. (22) showed that chromium supplementation led to greater insulin-stimulated glucose uptake in 3T3L1 adipocytes without an increase in insulin signaling. Their results indicated that there was an increase in the amount of GLUT4 near the plasma membrane in the basal state when chromium was present. However, glucose uptake was not increased unless insulin was added. The authors stated that since there was more GLUT4 near the plasma membrane, once insulin was added greater amounts of GLUT4 could be incorporated into the plasma membrane, leading to greater glucose uptake. This could explain the results seen in our study. A combination of more GLUT4 near the plasma membrane, and more fluidity in the plasma membrane, could result in an increase in plasma GLUT4 and glucose uptake without an alteration in insulin signaling.

Chromium has been shown to increase insulin signaling in insulin resistant muscles $(7,68,72)$. However, when non-insulin resistant muscles or adipose cultures 
were examined, there was no alteration in insulin signaling, but an increase in plasma membrane fluidity $(22,29,50)$. There is a possibility that both of these are viable mechanisms of chromium action. In insulin resistant muscles, in which the insulin signal is blunted, chromium may enhance insulin signaling to that of non-insulin resistant skeletal muscle. In non-insulin resistant muscle, the insulin signal is sufficient for adequate skeletal muscle glucose uptake. By altering plasma membrane fluidity, more GLUT4 can be incorporated into the plasma membrane, resulting in increased skeletal muscle glucose uptake.

In conclusion, we have determined that it is possible to increase insulin-stimulated glucose uptake with chromium supplementation in otherwise healthy skeletal muscle. Unfortunately, we were unable to determine how chromium increased glucose uptake under these conditions. As the mechanism of action of chromium has not yet been determined, future research should continue to examine how chromium supplementation increases glucose uptake. 


\section{Background Literature}

Chromium is an essential trace mineral with an atomic number of 51 . While this element can occur in many oxidation states, ranging from -2 to +6 , it is most commonly found in the trivalent oxidation state, since this is most stable $(3,43)$. Research into the necessity of chromium and its influence in the body began in Germany in 1959 (44). Chromium is commercially available in many different forms. Chromium chloride $\left(\mathrm{CrCl}_{3}\right)$ and chromium picolinate $(\mathrm{CrPic})$ are the most common found.

The main utilization for chromium has been for bettering glucose sensitivity. The results of studies analyzing the benefit of chromium supplementation in both humans and animals on glucose tolerance have been mixed. Chromium has also been investigated for control and digestion of lipids, lowering of blood pressure (54) as well as increasing lean body mass in farm animals (49).

Overall, the efficacy of chromium supplementation in humans regarding glucose disposal has been disputed. Although there are numerous studies exemplifying the benefits of chromium on certain populations, many others refute this. The evidence suggests chromium may only be effective in certain populations, namely diabetics and those with nutritional deficiencies. Chromium supplementation is thought to assist those with poor insulin signaling by increasing insulin's actions at different points along the insulin-signaling pathway, although the specific mechanism has not yet been determined.

\section{Chromium AbSorption}

One of the greatest difficulties when dealing with chromium supplementation is the absorption of chromium. MacKenzie et al. (41) analyzed radioactively labeled 
chromium compounds supplemented straight into the intestines, avoiding the initial steps of digestion. It was found that chromium (VI) was absorbed more efficiently and the blood concentration of chromium (VI) was significantly higher than the concentration of chromium (III). However, when chromium is supplemented orally, there is little difference in the valence activity of the element. Some researchers suggest that chromium (VI) is reduced to chromium (III) when ingested orally $(26,51)$. In humans (39), five subjects were given a liter of drinking water with different levels of chromium (VI) $(0.1,0.5,1.0,5.0$, and $10.0 \mathrm{mg}$ per liter $)$ added. The subjects ingested 1 liter of supplemented water a day, starting with the lowest concentration for three consecutive days before increasing the dosage. Observing the overall chromium concentration in both the plasma and red blood cells, the fluctuations occur similarly to ingestion of chromium (III). Earlier animal work has shown that when chromium (VI) is given intravenously or intratracheally, the plasma concentration levels drop at an accelerated rate compared to the red blood cell chromium concentrations $(28,32,69)$. However, in this study (39), after cessation of supplementation, there was a very rapid decrease in the red blood cell chromium concentration, similar to the decrease seen in plasma chromium concentration. Coogan et al. (24) demonstrated the differences in chromium kinetics in the red blood cells. This study showed that radioactively labeled chromium (VI) administered intravenously resulted in high concentrations in the blood while intravenous chromium (III) resulted in low levels of blood chromium that decreased rapidly after treatment. Additionally, orally administered chromium (VI) resulted in low levels of red blood cell chromium concentration that again decreased after administration. Therefore, 
it can be concluded that there are different kinetics for chromium depending on the method of administration. Regardless if this is due to the reduction of chromium (VI) to chromium (III) or some other phenomenon, it can be determined that while chromium (VI) shows efficient uptake when given directly in the blood compared with chromium (III), this advantage is negated when supplementation is done orally.

Anderson and Kozlovsky (10) examined subjects and their meals. The chromium levels in the food were analyzed, as well as urinary excretion of chromium and chromium absorption. The majority of subjects consumed levels of chromium below the dailyrecommended dosage, which is $50 \mu \mathrm{g}$ a day. In their study, Anderson and Kozlovsky found the mean ingestion of chromium for males was $33 \mu \mathrm{g}$ a day while women ingested an average of $25 \mu \mathrm{g}$ a day. The average urinary chromium excretion was $0.19 \mu \mathrm{g}$ daily, and excretion rates were not correlated with ingestion. The main finding in this study was that chromium absorption was inversely proportional to the amount of chromium ingested. The subjects who consumed the highest amounts of chromium had the lowest levels of absorption, whereas the subjects who consumed the lowest amounts of chromium had the highest levels of absorption. Subjects who ingested $10 \mu \mathrm{g}$ of chromium had absorption rates of approximately $2 \%$, while those who ingested $40 \mu \mathrm{g}$ of chromium had absorption rates of $0.45 \%$. When comparing all subjects, females had a significantly higher rate of chromium absorption when compared with men $(0.93 \%$ vs $0.64 \%)$. The difference in chromium absorption between men and women was due in part to the men taking in more calories. This data suggests that while chromium is essential for normal human physiological function, the amounts needed are extremely low. 
Theoretically, if higher ingestion rates result in lower levels of absorption, it would suggest that the body is able to tightly control the amount of chromium needed in the body.

Offenbacher et al. (48) performed a study on two men analyzing their chromium intake and excretion. These men were fed a controlled diet containing constant levels of micronutrients, minerals and chromium and were studied during two separate 6-day periods. The level of chromium intake was below the daily-recommended amount, as the men had average daily intake levels of 36.9 and $36.7 \mu \mathrm{g}$ a day. Of the amount eaten, the vast majority of the chromium was excreted in the stool, with a small amount excreted through the urine. Only a very small amount of chromium was absorbed in the body. The men had absorption levels of 0.6 and $0.2 \mu \mathrm{g}$ a day. This resulted in an average absorption rate between the two subjects of approximately $1.8 \%$. This study is somewhat problematic due to the low number of subjects as well as the subjects' ages, so it may not be applicable to a wider population. However, the data is along the lines of results in other studies, so it can be inferred that this is indeed an insightful look at chromium absorption.

A study by Kerger et al. (39) examined the absorption of multiple forms of chromium in humans. Chromium chloride, potassium dichromate with orange juice and potassium dichromate where studied for their absorption and excretion rates. The study showed that chromium chloride was the least absorbed $(0.13 \%)$ and most excreted while potassium dichromate was the most readily absorbed (6.9\%) and had the lowest rates of 
excretion. It should be noted that the chromium was taken in one high dose of $5 \mathrm{mg}$ of chromium dissolved in deionized water.

One reason for the poor absorption rate of chromium may be due to the speed at which it passes through the intestines. Oberleas et al. (47) fed a group of rats 1 gram meals containing radioactively labeled chromium chloride. One hour after the meal, animals were sacrificed. The majority of the chromium was found in the middle sections of the small intestines, whereas the majority of the rest of the meal was still located in the stomach. In rats that were sacrificed four hours after ingestion, the majority of the chromium had moved out of the small intestines. A significant amount of the chromium was found in the cecum as well as the colon. The authors speculate that, due to its chemical properties, chromium readily bonds with liquids, causing it to be released from the stomach and passed through the digestive tract rapidly. The poor levels of absorption seen with chromium are due to the speed with which it travels through the digestive tract according to the authors. While this may explain some reasons why chromium is poorly absorbed, it is certainly not the only factor. Other studies have shown that chromium absorption is inversely proportional to the amount ingested. Therefore, while the speed at which chromium moves through the digestive system may indeed deter chromium absorption, there must be other factors controlling chromium absorption.

\section{Necessity of Chromium}

Chromium is considered a necessary component of the diet (7). Multiple studies have shown humans and animals with low levels of chromium have impaired glucose 
uptake and metabolism. In individuals with low levels of chromium initially, supplementing with chromium results in an increase in glucose tolerance.

A classic case report published in 1977 was one of the first accounts of the necessity of chromium in the diet (38). A woman who had her intestines removed had to rely on intravenous nutrition. Her daily caloric intake was $1955 \mathrm{kcal} / \mathrm{day}$. After three years of this regiment, the woman's weight could not be maintained, and her glucose tolerance was impaired. In order to combat the impaired glucose tolerance, 45 units/day of insulin was added to her daily infusion. This was continued for another two years, and while glucose tolerance was maintained, she required an increase in calories to maintain her weight. The physicians tested her chromium levels and determined that she was chromium deficient. To improve the patient's chromium deficiency, $250 \mu \mathrm{g} /$ day of chromium was added to the infusion. In the absence of exogenous insulin, blood glucose levels were decreased from over $200 \mathrm{mg} / \mathrm{dL}$ two hours after infusion without chromium to less than $120 \mathrm{mg} / \mathrm{dL}$ two hours after infusion with chromium. When insulin was added along with chromium, the blood glucose levels were decreased even further. As the chromium treatment continued, the neuropathy seen was reversed, and exogenous insulin added to the infusion was no longer needed.

In rats, it has been repeatedly shown that chromium deficiency leads to insulin resistance $(46,51,61,63)$. Mertz et al. (46) raised rats on a chromium deficient diet, creating glucose intolerance. The rats had a glucose removal rate of $1.8 \%$, half of what is seen in normal rats. After receiving an intravenous injection of chromium of varying levels, glucose removal was improved to $3.5 \%$. Chromium was given in doses of 0.1 , 
0.25 and $0.5 \mu \mathrm{g}$ per $100 \mathrm{~g}$ body weight. The improvement was seen in the higher two doses, with no difference between the two treatments. This suggests that there is a plateau effect with chromium supplementation.

Striffler and colleagues (60) fed rats a low chromium, high sucrose diet to induce glucose intolerance before splitting the rats into a chromium supplemented group and a chromium deficient group. After 24 weeks, rats were subjected to an intravenous glucose tolerance test. Supplemented rats showed a lower area under the curve for their insulin response. The difference attributed to the chromium chloride supplementation was $43 \%$. Additionally, the glucose area under the curve was $18 \%$ lower in the chromium chloride supplemented group. Glucose clearance rates $\left(\mathrm{K}_{\mathrm{G}}\right)$ were also examined. It was determined that the chromium chloride supplemented group had a $\mathrm{K}_{\mathrm{G}}$ of $5.29 \%$ per minute while the chromium deficient group had a $\mathrm{K}_{\mathrm{G}}$ of $3.58 \%$ per minute. The authors stated this led to a $48 \%$ more efficient utilization of glucose in the chromium chloride supplemented group.

Additionally, a second study using a similar protocol was conducted, but was only performed for 12 weeks (63). In this study, rats were fed a basal diet high in sucrose and low in chromium to achieve chromium deficiency before the start of the study. Rats were then split into two groups, with one continuing on the chromium deficient diet and the other supplemented with $5 \mathrm{ppm}$ chromium chloride in the drinking water. After 12 weeks, rats were subjected to an intravenous glucose tolerance test. While both groups of rats showed similar rates of glucose uptake, the group that supplemented with chromium chloride had a significantly lower insulin response. The area under the curve for insulin 
secretion was two times higher in the deficient diet group compared to the supplemented group. A third group, used as a control, was included in the study and fed normal rat chow. The control group had a similar glucose uptake as the other groups, with the insulin area under the curve similar to the chromium chloride supplemented group. This study exemplifies the link between chromium and insulin resistance. In rats that were chromium deficient, more insulin was needed to elicit the same amount of glucose uptake. In rats that underwent chromium supplementation after becoming chromium deficient, the negative effects were reversed. The glucose uptake and insulin response in these experimental rats were similar to the control rats. This shows that chromium is necessary for proper glucose uptake and insulin efficiency.

\section{Chromium AND GLuCOSE INTOLERANCE}

In general, the results of studies on chromium and glucose tolerance have been mixed. A meta analysis by Balk et al. (16) showed that chromium supplementation is beneficial in populations with impaired insulin responses and glucose intolerance. The authors also determined that chromium supplementation is not beneficial in persons who have normal glucose tolerance. A meta-analysis by Althuis et al. (5) supports the hypothesis that chromium supplementation has no beneficial effects on persons with normal glucose tolerance. However, the authors additionally stated that results from studies conducted on subjects with type 2-diabetes are inconclusive. Of the studies investigated, only three analyzing type 2 diabetics met their criteria. Only one of these studies found a difference in glucose uptake or insulin levels during a glucose tolerance test (9). However, Althuis et al. (5) state that this study is not applicable to populations in 
the western hemisphere. The study was preformed in China and included subjects of very low body weight. This suggests that the subjects suffered from malnutrition, so the positive results may in fact be due to improvements in a chromium deficiency as a result of malnutrition.

A study by Frauchiger et al. (30) studied subjects who were healthy with normal glucose tolerance. The subjects were fed $75 \mathrm{~g}$ of carbohydrate in the form of white bread with either a placebo, $400 \mu \mathrm{g}$ or $800 \mu \mathrm{g}$ of chromium. The results showed that while there was a significant decrease in capillary blood glucose with chromium supplementation, there was no difference when venous glucose levels were examined. Additionally, subjects were analyzed individually. The subjects who had the highest glucose area under the curve showed the greatest improvement when chromium was supplemented. These results concur with other studies (13), in that chromium supplementation is only beneficial in populations who have impaired glucose tolerance. Anderson and colleagues (13) studied 11 females and 6 males. Subjects were separated into a hyperglycemic group and a control group. The criteria for the hyperglycemic group was a glucose concentration between 5.56 and $11.1 \mathrm{mmol} / \mathrm{L} 90$ minutes after an oral glucose tolerance test of 1 gram of glucose per kilogram of body weight. Subjects were given either a daily placebo or chromium supplement of $200 \mu \mathrm{g}$ of chromium chloride for four weeks, then given the other treatment for another four week period after a one week washout. The control group showed no difference between treatments while the hyperglycemic group showed significant differences. The glucose levels over 90 minutes for the control group were $21.2 \mathrm{mmol} / \mathrm{L}$ on the placebo treatment and 21.4 
$\mathrm{mmol} / \mathrm{L}$ on the chromium treatment. In the hyperglycemic group, glucose levels after 90 minutes were $30 \mathrm{mmol} / \mathrm{L}$ on the placebo treatment versus $26.5 \mathrm{mmol} / \mathrm{L}$ on the chromium treatment. Additionally, insulin levels were the same across treatments in the control group while chromium supplementation lowered insulin levels in the hyperglycemic group.

A second study by Anderson and colleagues (14) examined different populations and their reactions to chromium supplementation. Seventy-six subjects, both male and female were supplemented with $200 \mu \mathrm{g}$ of $\mathrm{CrCl}_{3}$ for three months or a placebo. This study was a cross over study, so each subject received both the placebo and experimental treatments. Two months into the supplementation period and at the end, subjects underwent an oral glucose tolerance test. Fasting glucose and insulin, as well as 90minute serum glucose and insulin levels were examined. When looking at the subjects as a whole, there were no significant changes. However, once the subjects were broken down into different groups, differences were seen. The groups formed were subjects with 90 minute glucose levels greater than or equal to $100 \mathrm{mg} / \mathrm{dl}$, subjects with 90 minute glucose levels less than or equal to fasting and subjects with 90 minute glucose levels less than $100 \mathrm{mg} / \mathrm{dl}$, but greater than fasting. In the group with the highest levels of serum glucose, chromium supplementation lead to a decrease in fasting glucose levels from 90 $\mathrm{mg} / \mathrm{dl}$ to $84 \mathrm{mg} / \mathrm{dl}$ whereas the subjects with glucose levels below $100 \mathrm{mg} / \mathrm{dl}$ showed no difference in resting glucose levels after three months of supplementation. Additionally, chromium supplementation led to decreases in 90-minute serum glucose levels in subjects with the highest glucose levels before supplementation. 90-minute glucose 
levels were lowered from $135 \mathrm{mg} / \mathrm{dl}$ to $115 \mathrm{mg} / \mathrm{dl}$ after three months. The subjects with glucose levels between resting and $100 \mathrm{mg} / \mathrm{dl}$ showed no difference after supplementation. Additionally, the group with the lowest initial 90-minute glucose levels showed an increase in 90-minute glucose levels after three months of chromium supplementation. This is concurrent with a second study by Anderson et al. (11) examining subjects with reactive hypoglycemia. Three months of supplementation with $200 \mu \mathrm{g} /$ day of chromium chloride resulted in an increase in serum glucose levels at two and four hours after an oral glucose tolerance test. These results suggest that chromium is necessary for proper glucose metabolism, whether subjects suffer from hypoglycemia or hyperglycemia.

Taken together, research focusing on chromium supplementation and glucose intolerance suggests that chromium supplementation helps with glucose metabolism in subjects exhibiting insulin resistance. It has been theorized that chromium increases the efficacy of insulin $(6,7,45)$. Therefore, chromium supplementation will not benefit those with normal glucose response and insulin action. Since chromium propagates insulin activity, those who must secrete increased levels of insulin to remove glucose from the blood stream will benefit from chromium supplementation. Less insulin will be needed to remove blood glucose since insulin action will be increased.

\section{MECHANISMS}

In general, the majority of studies agree that chromium increases insulinstimulated glucose uptake in skeletal muscle. However, there have been many different suggestions as to its mechanisms of action. Many studies have shown an increase in the 
insulin-signaling pathway as the mode of action for chromium $(6,44,46)$. There is much disagreement on which step in the complicated insulin-signaling cascade is altered. However, numerous studies have shown that chromium is ineffective without the presence of insulin $(22,55,72)$ suggesting that chromium does work in conjunction with insulin. Additionally, it has been suggested that chromium supplementation increases membrane fluidity $(31,50)$, resulting in increased glucose uptake.

Wang et al. (68) studied insulin resistant cell cultures treated overnight with multiple forms of chromium, all of which were in the +3 oxidation state. Once insulin was added, it was shown that chromium increased the tyrosine phosphorylation of the insulin receptor through an increase in activity of the insulin receptor tyrosine kinase. A study by Davis and Vincent (25) showed that chromium increases the tyrosine activity 8 times above that of normal activation. This study was performed in isolated rat adipocytes and additionally showed no chromium effect in the absence of insulin. In a second paper, Vincent proposed a mechanism of how chromium works (67). According to their results, insulin binding to the IR leads to an influx of chromium into the cell. The chromium will then bind to the insulin receptor, resulting in greater activation of the tyrosine kinase activity. As insulin levels drop, chromium is released from the receptor. Brautigan et al. (20) showed that pre-treating 3T3-L1 adipocytes with chromium and then adding insulin results in an increase of the insulin receptor tyrosine phosphorylation. Additionally, vanadate was studied with chromium and insulin. Vanadate is known to increase the tyrosine phosphorylation of the insulin receptor by inhibiting protein tyrosine phosphatases (PTP). PTP dephosphorylates the insulin receptor, decreasing the action of 
insulin. When combining insulin, vanadate and chromium, there was no increase in insulin receptor tyrosine phosphorylation above that of insulin and vanadate. It has been shown in other studies that chromium supplementation does not affect PTP activity (68). Therefore, while chromium does not inhibit insulin receptor dephosphorylation, it does increase tyrosine phosphorylation of the insulin receptor in some other manner.

Dong et al. (27) compared insulin resistant mice chronically supplemented with chromium with control mice. It was demonstrated that once the mice were stimulated with an intrapertional injection of insulin, the supplemented insulin resistant mice showed Akt phosphorylation in skeletal muscle on the same level of the control mice. These results were confirmed by Zhao et al (74). In cultured cardiac cells, it was shown that adding chromium and insulin increased Akt Ser ${ }^{473}$ phosphorylation after 15, 30 and 60 minutes above that of insulin alone. Additionally, when Wortmanin was added, 2-deoxy glucose uptake was significantly negated. Wortmanin is an inhibitor of PI-3 Kinase. PI3 Kinase is upstream of Akt in the insulin-stimulated cascade and must be activated in order to activated Akt downstream. This suggests that chromium affects the insulinsignaling cascade above Akt and not Akt directly.

In addition to chromium increasing insulin signaling through Akt, Zhao and colleagues (74) hypothesized that chromium increases signaling through AMPK. AMPK has been shown to play a role in insulin signaling and GLUT4 translocation $(40,73)$. In isolated mouse cardiac muscles, the addition of chromium (D-phenylalanine) ${ }_{3}$ increased $\mathrm{Thr}^{172}$ phosphorylation of AMPK. Additionally, there was an increase of acetyl-CoA carboxylase activation, a downstream substrate of AMPK. It was also shown that 
glucose uptake increased when adding chromium. However, the levels of glucose uptake were lowered when Compound $\mathrm{C}$, an inhibitor of AMPK, was added in addition to the chromium. These results suggest that chromium supplementation leads to greater glucose uptake through AMPK.

Chen et al. (22) investigated the effect of chromium on insulin-stimulated glucose transporter, GLUT4. The presence of GLUT4 on the plasma membrane was examined in 3T3-L1 adipocytes. In cell cultures pretreated with either chromium chloride or chromium picolinate, the amount of GLUT4 near the plasma membrane in the basal state was increased significantly compared to controls. Once insulin was added, GLUT4 translocation to the plasma membrane in the chromium treated cells was above normal. The authors concluded that the increase of GLUT4 on the plasma membrane was a result of an increase in membrane fluidity. This conclusion was based on the finding that treating 3T3-L1 adipocytes with chromium leads to a loss of cholesterol in the plasma membrane, leading to an increase in membrane fluidity. Other work from the same group used similar methods, examining membrane fluidity and insulin-stimulated GLUT4 translocation (50). It was found that chromium increased membrane fluidity through loss of cholesterol in the plasma membrane, which resulted in an increase in insulinstimulated GLUT4 translocation. Glucose uptake was not examined in the second study. Qiao and colleagues (55) examined chromium supplementation in rat L6 myoblasts. Three forms of chromium were investigated, chromium chloride $(\mathrm{CrCl})$, chromium picolinate ( $\mathrm{CrPic}$ ) and chromium chelated with small peptides (CrSP). Myoblasts were incubated in a medium containing chromium with and without insulin. 
The incubation lasted for 72 hours. In addition to investigating glucose uptake, mRNA expression levels of IR and GLUT4 were studied. In the presence of chromium alone, there was no increase in glucose uptake. When adding insulin to chromium supplementation, the CrPic and CrSP groups showed greater levels of glucose uptake than insulin alone. While glucose uptake in cells treated with $\mathrm{CrCl}$ was not significantly higher than cells treated with insulin alone, it was not significantly lower than the other two chromium groups. It was found that chromium supplementation alone led to an increase in the mRNA levels of IR, and when insulin was added, this increase was amplified. In cells treated with both chromium and insulin, there was an increase in the expression of GLUT4 mRNA.

\section{SUMMARY}

The efficacy of chromium supplementation is somewhat disputed. While many studies have shown that chromium improves glucose tolerance in certain populations, detractors have criticized these studies as being poorly controlled or not applicable to wide populations. However, there has been significant data proving the benefits of chromium. Even though these results cannot be applied to everyone, those populations with chromium deficiency or poor insulin response will in fact benefit from chromium supplementation.

One of the difficulties with evaluating chromium supplementation is the low level of absorption. The body does not need high levels of chromium in order to function properly, therefore the absorption levels of chromium are very low. Additionally, different forms of chromium are absorbed at different rates. This combined with 
differing levels of chromium in a self-selected diet make it difficult to properly evaluate the need and absorption rates of chromium supplementation.

Even though it has been shown that chromium increases glucose uptake, it has not been determined exactly how chromium does this. Different animal studies have shown that chromium may increase insulin receptor tyrosine phosphorylation, increase Akt activation, increase the amount of GLUT4 near the plasma membrane or increase membrane fluidity. The majority of studies have concluded that chromium increases glucose uptake only in the presence of insulin. Therefore, it can be concluded that chromium works in conjunction with insulin to stimulate glucose uptake. 


\section{Expanded Methodology}

\section{ANIMALS}

Twenty-eight male Sprague Dawley rats (Harlan, Houston, TX) were obtained for testing. Rats were received at 7 weeks of age. The rats were housed 2 to a cage and fed a standard laboratory chow (ProLab RMH 1800, Labdiet, Brentwood, MO) and provided with water ad libitum. The room housing the animals was kept at $21^{0} \mathrm{C}$ with an artificial 12 hour/12 hour light-dark cycle. Upon arrival, rats were randomly separated by weight into 1 of 4 groups: chromium with sub maximal insulin (Cr-sIns, $n=8)$, sub maximal insulin (sIns, $n=9)$, chromium without insulin $(C r, n=6)$, and basal (Bas, $n=5)$.

\section{EXPERIMENTAL DESIGN AND SURGERY}

In order to determine glucose uptake in the rat skeletal muscle, the hindlimb perfusion technique was utilized. Hindlimb perfusion has been shown to be both a viable and popular experimental model to examine skeletal muscle glucose metabolism under physiological conditions $(18,71)$.

Rats were subjected to testing at 9 weeks of age. After a 12-hour fast, rats were anesthetized with an intraperitoneal injection of pentobarbital sodium $(6.5 \mathrm{mg} / 100 \mathrm{~g}$ body weight). The surgical technique and the perfusion apparatus were similar to that previously described methods $(37,56)$. The purpose of the surgery was to tie off vessels in the abdominal cavity and the left limb while exposing the inferior vena cava and descending aorta. Cannulation of the right iliac artery and inferior vena cava could be performed, thus allowing the perfusate to flow from the arterial catheter, to the circulatory bed of the right hindlimb, and finally out through the venous catheter. 
Rats were placed on a heating pad in order to maintain normal body temperature throughout the surgery. A ligature was tied around the tail before a midline abdominal incision was made through the skin. The skin was reflected back and the superficial epigastric vessels were ligated. Next, an incision was made through the abdominal wall from the pubic symphysis to the ziphoid process. The stomach, spleen, pancreas and intestinal tract were removed from the cavity and wrapped in parafilm in order to increase access to the inferior vena cava and descending aorta. The hypogastric arteries were ligated as well as the testicle and inferior mesenteric arteries. The descending colon was ligated superior to the rectum and inferior to the xipohoid process then removed. The trunk of the bladder was then ligated. The iliolumbar arteries and veins, the right internal iliac artery and the right pubic-epigastric trunk were all ligated.

Next, loose ligatures were placed around the aorta and vena cava inferior to the renal vessels. A second ligature was placed around the vena cava superior to the iliolumbar vessels. A loose ligature was also placed around the left iliac artery.

The ligature around the descending aorta was tied and a small incision was made in the right iliac artery. A polyethylene catheter was inserted into the incision to the tip of the femoral artery. A $0.9 \% \mathrm{NaCl}$ solution was then pushed through the catheter from a $10 \mathrm{ml}$ syringe. The superior ligature around the inferior vena cava was tightened and the venous catheter was inserted and positioned below the distal ligature. The distal ligature was then tied in order to secure the catheter. Ten milliliters of $0.9 \% \mathrm{NaCl}$ was pushed through the arterial catheter, flushing the right hindlimb. After the catheters were in place, the rat was euthanized by an intracardiac injection of pentobarbital sodium. 


\section{Hindlimb Perfusion}

All solutions for the perfusion procedure were prepared in $6 \%$ BSA. $2 \mathrm{mM}$ Na-pyruvate was added to the $6 \%$ BSA for the basal washout solution. The Bas perfusate solution contained $2 \mathrm{mM}$ Na-pyruvate, $6 \mathrm{mM}$ glucose, $2 \mathrm{mM}$ mannitol, $0.2 \mu \mathrm{Ci} / \mathrm{ml} \mathrm{H}^{3}-2$ deoxyglucose and $0.15 \mu \mathrm{Ci} / \mathrm{ml} \mathrm{C}^{14}$-Sucrose. The washout solution for the $\mathrm{Cr}$ group contained $2 \mathrm{mM}$ Na-pyruvate and $0.096 \mu \mathrm{M} \mathrm{CrCl}_{3}$. The $\mathrm{Cr}$ perfusate solution was composed of $2 \mathrm{mM}$ Na-pyruvate, $0.096 \mu \mathrm{M} \mathrm{CrCl}_{3}, 6 \mathrm{mM}$ glucose, $2 \mathrm{mM}$ mannitol, 0.2 $\mu \mathrm{Ci} / \mathrm{ml} \mathrm{H}^{3}-2$ deoxyglucose and $0.15 \mu \mathrm{Ci} / \mathrm{ml} \mathrm{C}^{14}$-Sucrose. The washout solution for the sIns group was made of $2 \mathrm{mM}$ Na-pyruvate and $200 \mu \mathrm{U} / \mathrm{ml}$ insulin. The perfusate solution contained $2 \mathrm{mM}$ Na-pyruvate, $200 \mu \mathrm{U} / \mathrm{ml}$ insulin, $6 \mathrm{mM}$ glucose, $2 \mathrm{mM}$ mannitol, $0.2 \mu \mathrm{Ci} / \mathrm{ml} \mathrm{H}^{3}-2$ deoxyglucose and $0.15 \mu \mathrm{Ci} / \mathrm{ml} \mathrm{C}^{14}$-Sucrose. The Cr-sIns washout solution was made of $2 \mathrm{mM}$ Na-pyruvate, $200 \mu \mathrm{U} / \mathrm{ml}$ insulin and $0.096 \mu \mathrm{M}$ $\mathrm{CrCl}_{3}$. The perfusate solution for the Cr-sIns group contained $2 \mathrm{mM}$ Na-pyruvate, 200 $\mu \mathrm{U} / \mathrm{ml}$ insulin, $0.096 \mu \mathrm{M} \mathrm{CrCl}_{3}, 6 \mathrm{mM}$ glucose, $2 \mathrm{mM}$ mannitol, $0.2 \mu \mathrm{Ci} / \mathrm{ml} \mathrm{H}^{3}-2$ deoxyglucose and $0.15 \mu \mathrm{Ci} / \mathrm{ml} \mathrm{C}^{14}$-Sucrose.

The cannulated rat was placed in line with the perfusion system. The perfusate was continuously mixed on a magnetic stir plate. The perfusate first passed through a roller pump, which was calibrated at $6 \mathrm{ml} / \mathrm{min}$ for the washout and $3 \mathrm{ml} / \mathrm{min}$ for the perfusate. The perfusate then passed through approximately 3 meters of Silastic tubing (Dow Corning, Midland, MI) contained in an artificial lung, which was gassed with a mixture of $95 \% \mathrm{O}_{2}$ and $5 \% \mathrm{CO}_{2}$. Next, the perfusate passed through a heated water jacket maintained at $37^{\circ} \mathrm{C}$, and then through a bubble trap before entering the hindlimb of 
the rat via the arterial catheter. After circulating through the right hindlimb, the perfusate exited through the venous catheter and was collected in a beaker on ice for later analysis.

A manometer was placed in line after the bubble trap. The pressure of the system ranged from 25 to $30 \mathrm{mmHg}$ during the perfusion process. The entire system was housed in a Plexiglas chamber, accessible from the front. The rat was placed on a heating pad to maintain circulation.

The hindlimb was allowed to stabilize during a 10 minute washout period. After the washout period, the rat was perfused for 25 minutes with the nonrecirculating perfusate solution. Aliquots of the arterial samples were taken in order to determine the specific activity of the isotopes to help determine the skeletal muscle glucose uptake. After the perfusion was performed, the right gastrocnemius and quadriceps were removed, freeze clamped in liquid nitrogen and stored at $-80^{\circ} \mathrm{C}$ for later analysis.

\section{Tissue Preparation for Glucose Uptake}

Pieces of frozen gastrocnemius and quadriceps were cut and weighed. The pieces were digested in $1 \mathrm{ml}$ of $1 \mathrm{M} \mathrm{KOH}$ for 20 minutes at $60^{\circ} \mathrm{C}$. The digested muscle was neutralized with $1 \mathrm{ml}$ of $1 \mathrm{M}$ HCL before $300 \mu \mathrm{l}$ of the mixture was added to $6 \mathrm{ml}$ BioSafe II scintillation cocktail (Research Products International, Mt. Prospect, IL). An LS-6500 Multi Purpose Scintillation Counter (Beckman Coulter, Inc., Brea CA) was used to count duplicate samples of ${ }^{3} \mathrm{H}$ and ${ }^{14} \mathrm{C}$. Uptake of 2-DG in the muscle was calculated as the difference between total muscle 2-DG and extracellular 2-DG. Extracellular space was determined from the from tissue concentration of $\left[{ }^{14} \mathrm{C}\right]$-Sucrose, since the sucrose cannot cross the plasma membrane (34-36). 


\section{WESTERN BLOTTING}

Frozen gastrocnemious muscle was pulverized in a mortar and pestle in liquid nitrogen. Homogenization buffer (20mM Hepes, 2mM EGTA, $50 \mathrm{mM} \mathrm{NaF}, 100 \mathrm{mM}$ $\mathrm{KCl}, 0.2 \mathrm{mM}$ EDTA, $50 \mathrm{mM}$ glycerophosphate, $1 \mathrm{mM}$ DTT, $0.1 \mathrm{mM}$ PMSF, 1mM Benzamidine, $0.5 \mathrm{mM}$ Na Vanadate) was added to the chilled mortar. After pulverization, the powdered muscle was added to a glass tissue grinder (Corning Stirrer Type RZR1, Wiarton, Ont. Canada) with additional homogenization buffer to dilute the sample at a dilution factor of 9:1. The samples were thoroughly mixed in the grinder for 10 seconds 3 times each. The homogenate was then centrifuged at $4^{0} \mathrm{C}$ for 10 minutes at $14,000 \mathrm{x}$ g. Following the centrifugation, the protein concentration of the supernatant was analyzed using the Bradford method (19) (Bio-Rad Laboratories, Hercules, CA). The supernatant was then aliquoted into multiple vials and stored at $-80^{\circ} \mathrm{C}$ until analyzed.

When the Western analysis was performed, an aliquot was thawed and diluted with sample buffer $(5 \mathrm{ml} 1.25 \mathrm{M}$ Tris, $10 \mathrm{ml}$ glycerol, $5 \mathrm{ml} 20 \% \mathrm{SDS}, 2.25 \mathrm{ml}$ betamercaptoethanol, $1.6 \mathrm{ml} 0.25 \%$ Bromophenol Blue) at a $1: 1$ ratio followed by a denaturing of the sample for 7 minutes in water heated to $95^{\circ} \mathrm{C}$. Duplicate samples containing $40 \mu \mathrm{g}$ of protein were separated on $10 \%$ polyacrylamide gels by sodium dodecyl sulfate polyacrylamide gel electrophoresis (SDS-PAGE, Bio-Rad Laboratories, Richmond, CA) for 120 minutes at $160 \mathrm{~V}$. The proteins were then electrophoretically transferred at $85 \mathrm{~V}$ for 120 minutes from the polyacrylamide gels onto nitrocellulose membranes (Millipore, Corp., Bedford, MA) using a wet transfer unit (Bio-Rad Laboratories, Hercules, CA). Membranes were cut at the $100 \mathrm{kDa}$ marker, with the upper 
portion probed for AS160 and the lower probed for Akt. Membranes were blocked with a 7\% solution of Tris-Tween bufferd saline (TTBS) and non-fat dry milk (NFDM) for 1 hour. Membranes were then washed 3 times for 5 minutes then incubated overnight with primary antibody diluted 1:800 in TTBS with $2 \%$ non-fat dry milk. The antibodies used were specific for the proteins examined; phosphorylated AS160 (Thr642 \#4288S), phosphorylated Akt(Thr308, \#4056S), total AS160 (Anti-AS160 Rab-GAP Rabbit antiserum) and total Akt (Akt Rabbit Ab). All antibodies were purchased from Cell Signaling Technology (Danvers, MA) except total AS160, which was purchased from Upstate (Temecula, CA).

Following the overnight incubation, the membranes were washed with TTBS 3 times for 5 minutes and then incubated for 90 minutes in secondary antibody (anti-rabbit, HRP-linked IgG, \#7974, Cell Signaling Technology) that was diluted to 1:750 in 2\% TTBS and NFDM for all proteins examined. After further washing, the membranes were placed in enhanced chemiluminescence reagent (Perkins Elmer, Boston, MA) for two minutes. A Molecular Imager Chemidoc XRS (Bio-Rad Laboratories, Hercules, CA) was used in order to visualize the proteins. Quantity One Analysis Software (Bio-Rad Laboratories, Hercules, CA) was used to quantify the mean density of the bands. After exposure of phosphorylated proteins, membranes were placed in a stripping buffer $(\mathrm{pH}$ 6.7, $7.5 \mathrm{~g}$ Tris Base, $20 \mathrm{~g}$ SDS, $7 \mathrm{ml} \beta$-me) for one hour. Membranes were then washed 2 times for 5 minutes and then probed for total protein. Akt and AS160 phosphorylation was analyzed as a percentage of total Akt and AS160. 


\section{Appendix A - Muscle Homogenization}

Homogenization Buffer for Western Immunoblotting (100 ml, pH 7.4):

- 20 mM HEPES (H-3378)

- 2 mM EGTA (E-4378)

$-50 \mathrm{mM} \mathrm{NaF}(\mathrm{S}-7920)$

$\begin{array}{ll}\rightarrow & 0.4766 \mathrm{~g} \\ \rightarrow & 0.0761 \mathrm{~g} \\ \rightarrow & 0.209 \mathrm{~g} \\ \overrightarrow{ } & 0.746 \mathrm{~g} \\ \overrightarrow{ } & 0.0074 \mathrm{~g} \\ \overrightarrow{ } & 1.08 \mathrm{~g} \\ \overrightarrow{ } & 0.015 \mathrm{~g} \\ \vec{\rightarrow} & 0.00174 \mathrm{~g} \\ \rightarrow & 0.01566 \mathrm{~g} \\ \rightarrow & 0.0092 \mathrm{~g}\end{array}$

Homogenization:

1. Frozen muscle was pulverized in a liquid nitrogen cooled mortar and pestle with homogenization buffer

2. Homogenize muscle on ice ( $3 \times 10 \mathrm{sec}$ strokes) with glass tissue grinder pestle

(Corning Life Sciences, Acton, MA) that is rotated by an electrically powered stirrer

(Caframo Stirrer Type RZR1, Wiarton, Ont. Canada) at $3000 \mathrm{rpm}$

3. Aliquot supernatants into $1.5 \mathrm{ml}$ Eppendorf tubes (approximately $80 \mu \mathrm{l}$ per tube), and store at $-80^{\circ} \mathrm{C}$. 


\section{Appendix B - Krebs Buffer}

\section{Preparation of Krebs-Henseleit Buffer (KHB):}

Prepare Stock 1 and 2:

KHB Stock 1 (1 L)

\begin{tabular}{llll}
\hline Chemical & Concentration & Amount $(\mathrm{g})$ & FW \\
$\mathrm{NaCl}$ & $1.16 \mathrm{M}$ & 67.79 & 58.44 \\
$\mathrm{KCl}$ & $46 \mathrm{mM}$ & 3.429 & 74.56 \\
$\mathrm{KH}_{2} \mathrm{PO}_{4}$ & $11.6 \mathrm{mM}$ & 1.578 & 136.1 \\
$\mathrm{NaHCO}_{3}$ & $253.0 \mathrm{mM}$ & 21.25 & 84.01 \\
\hline
\end{tabular}

KHB Stock 2 (1 L)

\begin{tabular}{llll}
\hline Chemical & Concentration & Amount $(\mathrm{g})$ & $\mathrm{FW}$ \\
$\mathrm{CaCl}_{2} \cdot 2 \mathrm{H}_{2} \mathrm{O}$ & $25 \mathrm{mM}$ & 3.675 & 147 \\
$\mathrm{MgSO}_{4} \cdot 7 \mathrm{H}_{2} \mathrm{O}$ & $11.6 \mathrm{mM}$ & 2.859 & 246.48 \\
\hline
\end{tabular}

Prepare 1 L KHB for dissolving BSA

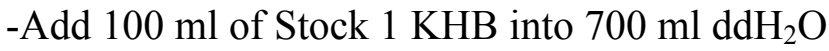

-Gas with $0_{2} / \mathrm{CO}_{2}(95 \% / 5 \%)$ for $45 \mathrm{~min}$

-Add $100 \mathrm{ml}$ of Stock 2 KHB

-Bring to $1 \mathrm{~L}$ with $\mathrm{ddH}_{2} \mathrm{O}$

Prepare 6\% BSA

-Add $90 \mathrm{~g}$ BSA on top of $390 \mathrm{ml}$ of gassed KHB

-Stir until dissolved

-Add dissolved BSA into a dialysis tube then clamp end of tube to prevent leaking

-Place dialysis tube into a tank containing $15 \mathrm{~L}$ of KHB and stir for 48 hours

-Check concentration with refractometer 
-Filter twice though micropore paper using a vacuum pump

-Using the refractomter bring the BSA concentration to $6 \%$ with gassed BSA 


\section{Appendix C - Wet Transfer Buffer}

\section{Preparation of Wet Transfer Buffer}

Wet transfer buffer (2 L)

\begin{tabular}{lll}
\hline Chemical & Concentration & Amount \\
Tris & $25 \mathrm{mM}$ & $6.06 \mathrm{~g}$ \\
Glycine & $192 \mathrm{mM}$ & $28.8 \mathrm{~g}$ \\
Methanol & $20 \%$ & $400 \mathrm{ml}$
\end{tabular}

-Add Tris, Glycine and Methanol to $1 \mathrm{~L}$ of $\mathrm{ddH}_{2} \mathrm{O}$

-Bring to volume of $2 \mathrm{~L}$ with $\mathrm{ddH}_{2} \mathrm{O}$ 


\section{Appendix D - Protein Assay (Bradford)}

\section{Bradford Protein Assay}

\section{Standard Protocol}

1. Remove the $1 \mathrm{x}$ dye reagent from $4^{0} \mathrm{C}$ storage and let it warm to ambient temperature. Invert the $1 \mathrm{x}$ dye a few times before use.

2. To generate a standard curve, use $2 \mathrm{mg} / \mathrm{ml} \mathrm{BSA}$. For the diluent, use the same buffer as in the samples. Protein solutions are performed in duplicate. Prepare the standard curve as follows:

\begin{tabular}{|c|c|c|c|c|}
\hline Tube \# & $\begin{array}{c}\text { Standard Volume } \\
(\boldsymbol{\mu} \mathbf{L})\end{array}$ & $\begin{array}{c}\text { Source of } \\
\text { Standard }\end{array}$ & $\begin{array}{c}\text { Diluent Volume } \\
(\boldsymbol{\mu} \mathbf{L})\end{array}$ & $\begin{array}{c}\text { Final [Protein] } \\
(\boldsymbol{\mu g} / \mathbf{m l})\end{array}$ \\
\hline 1 & 70 & $2 \mathrm{mg} / \mathrm{ml}$ stock & 0 & 2,000 \\
\hline 2 & 75 & $2 \mathrm{mg} / \mathrm{ml}$ stock & 25 & 1,500 \\
\hline 3 & 70 & $2 \mathrm{mg} / \mathrm{ml}$ stock & 70 & 1,000 \\
\hline 4 & 35 & Tube 2 & 35 & 750 \\
\hline 5 & 70 & Tube 3 & 70 & 500 \\
\hline 6 & 70 & Tube 5 & 70 & 20 \\
\hline 7 & 70 & Tube 6 & 70 & 125 \\
\hline 8 (blank) & 0 & 0 & 70 & 0 \\
\hline
\end{tabular}

3. To duplicate $12 \times 75 \mathrm{~mm}$ glass assay tubes, add $20 \mu \mathrm{l}$ of each standard and unknown sample solution. Add $1 \mathrm{ml}$ of $1 \mathrm{x}$ dye reagent to each tube and vortex.

4. Incubate at room temperature for $30 \mathrm{~min}$.

5. Set the spectrophotometer to $595 \mathrm{~nm}$. Zero the instrument with the blank. Measure absorbance of the standards and unknown samples. 


\section{Appendix E - Individual Muscle Data}

Glucose uptake data

\begin{tabular}{cllr}
\hline Rat & Treatment & $\begin{array}{l}\text { Quad Glucose Uptake } \\
(\boldsymbol{\mu m o l} / \mathbf{g} / \mathbf{h})\end{array}$ & \multicolumn{2}{c}{$\begin{array}{l}\text { Gast Glucose Uptake } \\
(\boldsymbol{\mu m o l} / \mathbf{g} / \mathbf{h})\end{array}$} & \\
\hline 2 & Cr-sIns & 4.27 & 5.68 \\
\hline 4 & Cr-sIns & 6.09 & 8.10 \\
\hline 5 & Cr-sIns & 7.97 & 11.22 \\
\hline 8 & Cr-sIns & 5.51 & 6.29 \\
\hline 10 & Cr-sIns & 9.33 & 6.84 \\
\hline 12 & Cr-sIns & 9.42 & 5.13 \\
\hline 14 & Cr-sIns & 5.01 & 7.12 \\
\hline 27 & Cr-sIns & 5.79 & 4.51 \\
\hline 1 & sIns & 2.69 & 4.89 \\
\hline 3 & sIns & 3.56 & 5.44 \\
\hline 7 & sIns & 5.89 & 6.47 \\
\hline 9 & sIns & 6.85 & 5.04 \\
\hline 11 & sIns & 4.68 & 5.52 \\
\hline 13 & sIns & 5.00 & 6.09 \\
\hline 15 & sIns & 4.66 & 3.28 \\
\hline 30 & sIns & 3.41 & 3.98 \\
\hline 33 & sIns & 4.16 & 2.75 \\
\hline 18 & Cr & 1.75 & 1.63 \\
\hline 21 & Cr & 1.39 & 1.26 \\
\hline 22 & Cr & 1.09 & 0.99 \\
\hline 25 & Cr & 1.59 & 1.59 \\
\hline 29 & Cr & 0.91 & 1.79 \\
\hline 34 & Cr & 0.80 & 1.01 \\
\hline 17 & Bas & 1.46 & 2.59 \\
\hline 19 & Bas & 1.51 & 1.71 \\
\hline 20 & Bas & 0.97 & 2.22 \\
\hline 24 & Bas & 1.28 & 1.07 \\
\hline 32 & Bas & 1.58 & 1.03 \\
\hline & & & \\
\hline & & & \\
\hline
\end{tabular}

Western blotting data

\begin{tabular}{rlrc}
\hline Rat & Treatment & p-Akt/t-Akt & p-AS160/t-AS160 \\
\hline 2 & Cr-sIns & $36 \%$ & $12 \%$ \\
\hline 4 & Cr-sIns & $19 \%$ & $56 \%$ \\
\hline 5 & Cr-sIns & $29 \%$ & $15 \%$ \\
\hline 8 & Cr-sIns & $23 \%$ & $45 \%$ \\
\hline
\end{tabular}




\begin{tabular}{clcc}
\hline 10 & Cr-sIns & $24 \%$ & $46 \%$ \\
\hline 12 & Cr-sIns & $18 \%$ & $41 \%$ \\
\hline 14 & Cr-sIns & $23 \%$ & $38 \%$ \\
\hline 27 & Cr-sIns & $15 \%$ & $44 \%$ \\
\hline 1 & sIns & $35 \%$ & $14 \%$ \\
\hline 3 & sIns & $19 \%$ & $17 \%$ \\
\hline 7 & sIns & $13 \%$ & $54 \%$ \\
\hline 9 & sIns & $25 \%$ & $62 \%$ \\
\hline 11 & sIns & $38 \%$ & $57 \%$ \\
\hline 13 & sIns & $34 \%$ & $13 \%$ \\
\hline 15 & sIns & $18 \%$ & $14 \%$ \\
\hline 30 & sIns & $6 \%$ & $37 \%$ \\
\hline 33 & sIns & $14 \%$ & $59 \%$ \\
\hline 18 & Cr & $2 \%$ & $5 \%$ \\
\hline 21 & Cr & $2 \%$ & $21 \%$ \\
\hline 22 & Cr & $1 \%$ & $4 \%$ \\
\hline 25 & Cr & $5 \%$ & $20 \%$ \\
\hline 29 & Cr & $5 \%$ & $18 \%$ \\
\hline 34 & Cr & $7 \%$ & $15 \%$ \\
\hline 17 & Bas & $2 \%$ & $3 \%$ \\
\hline 19 & Bas & $3 \%$ & $12 \%$ \\
\hline 20 & Bas & $2 \%$ & $6 \%$ \\
\hline 24 & Bas & $7 \%$ & $27 \%$ \\
\hline 32 & Bas & $5 \%$ &
\end{tabular}




\section{References}

1. The American Diabetes Association. Evidence-based nutrition principles and recomendations for the treatment and prevention of diabetes and related complications. Diabetes Care 26: S51-S61, 2003.

2. Office of Dietary Supplements: Dietary supplement fact sheet: chromium [article online] [June 18, 2010].

3. Review of Chromium. Expert Group on Vitamins and Minerals Secretariat 2002.

4. World Health Organization (Department of Noncommunicable Disease

Surveillance, Geneva, 1999) Definition, diagnosis and classification of diabetes mellitus and its complications. Part 1: Diagnosis and classification of diabetes mellitus. 1-59, 1999.

5. Althuis MD, Jordan, N.E., Ludington, E.A., Wittes, J.T. Glucose and insulin responses to dietary chromium supplements: a meta-analysis. The American Journal of Clinical Nutrition 76: 148-155, 2002.

6. Anderson RA. Chromium metabolism and its role in disease processes in man. Clinical Physiology and Biochemistry 4: 31-41, 1986.

7. Anderson RA. Chromium, glucose intolerance and diabetes. Journal of the American College of Nutrition 17: 548-555, 1998.

8. Anderson RA, Bryden, N.A., Polansky, M.M. Serum chromium of human subjects: effects of chromium supplementation and glucose. Am J Clin Nutr 41: 571-577, 1985.

9. Anderson RA, Cheng, N., Bryden, N., Polansky, M.M., Cheng, N., Chi, J., Feng, J. Elevated intakes of supplemenal chromium improve glucose and insulin variables in individuals with type 2 diabetes. Diabetes 46: 1786-1791, 1997.

10. Anderson RA, Kozlovsky, A.S. Chromium intake, absorption and excretion of subjects consuming self-selected diets. The American Journal of Clinical Nutrition 41: 1177-1183, 1985.

11. Anderson RA, Polansky, M.M., Bryden, N.A., Bathena, S.J., Canary, J. Effects of Supplemental Chromium on Patients With Symptoms of Reactive Hypoglycemia. Metabolism 36: 351-355, 1987.

12. Anderson RA, Polansky, M.M., Bryden, N.A., Bathena, S.J., Canary, J. Effects of supplemental chromium on patients with symptoms of reactive hypoglycemia. Metabolism 36: 351-355, 1987.

13. Anderson RA, Polansky, M.M., Bryden, N.A., Canary, J. Supplementalchromium effects on glucose, insulin, glucagon, and urinary chromium losses in subjects consuming controlled low-chromium diets. The American Journal of Clinical Nutrition 54: 909-916, 1991.

14. Anderson RA, Polansky, M.M., Bryden, N.A., Roginski, E.E., Mertz, W., Glinsmann. Chromium Supplementation of Human Subjects: Effects on Glucose, Insulin, and Lipid Variables. Metabolism 32: 894-899, 1983. 
15. Astrup A, Finer, N. Redefining type 2 diabetes: 'Diabetes' or 'Obesity Dependent Diabetes Mellitus'? Obesity Reviews 1: 57-59, 2000.

16. Balk EM, Tatsioni, A., Lichtenstein, A.H., Lau, J., Pittas, A.G. Effect of chromium supplementation on glucose metabolism and lipids. Diabetes Care 30: 21542163, 2007.

17. Barnard ND, Cohen, J., Jenkins, D.J.A., Turner-McGrievy, G., Gloede, L., Green, A., and Ferdowsian, H. A low-fat vegan diet and a conventional diabetes diet in the treatment of type 2 diabetes: a randomized, controlled, 74-wk clinical trial. Am J Clin Nutr 89: 1588S-1596S, 2009.

18. Bonen A, Clark, M.G., Henriksen, E.J. Experimental approaches in muscle metabolism: hindlimb perfusion and isolated muscle incubations. Am J Physiol Endocrinol Metab 266: E1-E16, 1994.

19. Bradford MM. A rapid and sensitive method for the quantitation of microgram quantities of protein utilizing the principle of protein-dye binding. Analytical Biochemistry 72: 248-254, 1976.

20. Brautigan DL, Kruszewski, A., Wang, H. Chromium and vanadate comination increases insuli-induced glucose uptake by 3T3-L1 adipocytes. Biochemical and Biophysical Research Communications 347: 769-773, 2006.

21. Cartee GD, and Wojtaszewski, J.F.P. Role of Akt substrate of $160 \mathrm{kDa}$ in insulin-stimulated and contraction-stimulated glucose transport. Appl Physiol Nutr Metab 32: 557-566, 2007.

22. Chen G, Liu, P., Pattar, G.R., Tackett, L., Bhonagiri, P., Strawbridge, A.B., EImendorf, J.S.,. Chromium Activates Glucose Transporter 4 Trafficking and Enhances Insulin-Stimulated Glucose Transport in 3T3-L1 Adipocytes via a Cholesterol-Dependent Mechanism. Molecular Endrocrinology 20: 857-870, 2006.

23. Cline GW, Petersen, K. F., Krssak, M., Shen, J., Hundal, R.S., Trajanoske, Z., Inzucchi, S., Dresner, A., Rothman, D.L., Shulman, G. I. Impaired glucose transport as a cause of decreased insulin-stimulated muscle glycogen synthesis in type 2 diabetes. The New England Journal of Medicine 341: 240-246, 1999.

24. Coogan TP, Squibb, K.S., Motz, J., Kinney, P.L., Cost, M. Distribution of chromium within cells of the blood. Toxicology and Applied Pharmacology 108: 157$166,1991$.

25. Davis CM, Vincent, J.B. Chromium oligopeptide activates insulin receptor tyrosine kinase activity. Biochemistry 36: 4382-4385, 1997.

26. Doisy RJ, Streeten, D.H.P., Freiberg, J.M., Schneider A.J. Chromium metabolism in man and biochemical effects. Trace Elements in Human Health and Disease Essential and Toxic Elements 2: 79-104, 1976.

27. Dong F, Kandadi, M.R., Ren, J., Sreejayan, N. Chromium (D-phenylalanine)3 Supplementation Alters Glucose Disposal, Insulin Signaling, and Glucose Transporter-4 Membrane Translocation in Insulin-Resistant Mice. The Journal of Nutrition 138: 1846$1851,2008$.

28. Edel J, and Sabbioni, E. Pathways of $\mathrm{Cr}(\mathrm{III})$ and $\mathrm{Cr}(\mathrm{VI})$ in the rat after intratracheal administration. Human Toxicol 4: 409-416, 1985. 
29. Evans GW, and Bowman, T.D. Chromium picolinate increases membrane fluidity and rate of insulin internalization. Journal of Inorganic Biochemistry 46: 243$250,1992$.

30. Frauchiger MT, Wenk, C., Colombani, P.C. Effects of acute chromium supplementation on postprandial metabolism in healthy young men. Journal of the American College of Nutrition 23: 351-357, 2004.

31. Garcia JJ, Martinez-Ballarin, E., Millan-Plano, S., Allue, J.L., Albendea, C., Fuentes, L., Escanero, J.F. Effects of trace elements on membrane fluidity. Journal of Trace Elements in Medicine and Biology 19: 19-22, 2005.

32. Gray SJ, and Sterling, K. The tagging of red blood cells and plasma proteins with radioactive chromium. J Clin Invest 29: 1604-1613, 1950.

33. Gregoire JP, Sirosi, C., Blanc, G., Poirier, P., Moisan, J. Persistence patternse with oral antidiabetes drug treatment in newly treated patients- a population-based study. ISPOR 13: 820-828, 2010.

34. Hunt DG, Ding, Z., Ivy, J.L. Clenbuterol prevents epinephrine from antagonizing insulin-stimulated muscle glucose uptake. J Appl Physiol 92: 1285-1292, 2002.

35. Hunt DG, Ding, Z., Ivy, J.L. Epinephrine inhibits insulin-stimulated muscle glucose transport. J Appl Physiol 93: 1638-1643, 2002.

36. Hunt DG, Ding, Z., Ivy, J.L. Propranolol prevents epinephrine from antagonizing insulin-stimulated muscle glucose uptake. J Appl Physiol 93: 697-704, 2002.

37. Ivy JL, Brozinick Jr., J.T., Torgan, C.E., Kastello, G.M. Skeletal muscle glucose transport in obese Zucker rats after exercise training. J Appl Physiol 66: 2635$2641,1989$.

38. Jeejeebhoy KN, Chu, R.C., Marlis, E.B., Greenberg, G.R., Bruce-Robertson, A. Chromium deficiency, glucose intolerance, and neuropathy reversed by chromium supplemenation, in a patient receiving long-term total parenternal nutrition. The American Journal of Clinical Nutrition 30: 531-538, 1977.

39. Kerger BD, Paustenbach, D.J., Corbett, G.E., Finley, B.L. Absorption and elimination of trivalent and hexavalent chromium in humans following ingestion of a bolus dose in drinking water. Toxicology and Applied Pharmacology 141: 145-158, 1996. 40. Li J, Hu, X., Selvakumar, P., Russell, R.R. III., Cushman, S.W., Holman, G.D. and Young, L.H. Role of the nitric oxide pathway in AMPK-mediated glucose uptake and GLUT4 translocation in heart muscle. Am J Physiol-Endoc M 287: E834E841, 2004.

41. MacKenzie RD, Anwar, R.A., Byerrum, R.U., Hoppert, C.A. Absorption and Distribution of Cr-51 in the Albino Rat. Archives of Biochemistry and Biophysics 79: 200-205, 1959.

42. Manning BD, Cantley, L.C. AKT/PKB signaling: navigating downstream. Cell 129: 1261-1274, 2007.

43. Mertz W. Chromium Occurence and Function in Biological Systems. Physiological Reviews 49: 163-240, 1969. 
44. Mertz W. Chromium Research from a Distance: From 1959 to 1980. Journal of the American College of Nutrition 17: 544-548, 1998.

45. Mertz W. Interaction of chromium with insulin: A progress report. Nutrition Reviews 56: 174-177, 1998.

46. Mertz W, Roginski, E.E., Reba, R.C. Biological activity and fate of trace quantities of intravenous chromium(III) in the rat American Journal of Physiology 209: 489-494, 1965.

47. Oberleas D, Li, Y.C., Stoecker, B.J., Henley, S.A., Keim, K.S., Smith Jr, J.C. The rate of chromium transit through the gastrointestinal tract. Nutrition Research 10: 1189-1194, 1990.

48. Offenbacher EG, Spencer, H., Dowling, H.J., Pi-Sunyer, F.X. Metabolic chromium balances in men. The American Journal of Clinical Nutrition 44: 77-82, 1986. 49. Page TG, Southern, L.L., Ward, T.L., Thompson, D.L. Jr. Effects of chromium picolinate on growth and serum and carcass traits of growing-finishing pigs. $J$ Anim Sci 71: 656-662, 1993

50. Pattar GR, Tackett, L., Liu, P., Elmendorf, J.S. Chromium picolinate positively influences the glucose transporter system via affecting cholesterol homeostasis in adipocytes cultured under hyperglycemic diabetic conditions. Mutation Research 610: 93-100, 2006.

51. Pechova A, and Pavlata, L. Chromium as an essential nutrient: a review. Veterinarni Medicina 52: 1-18, 2007.

52. Pei D, Hsieh, C.H., Hung, Y.J., Li, J.C., Lee, C.H., Kuo, S.W. The influence of chromium chloride-containing milk to glycemic control of patients with type 2 diabetes mellitus: a randomized, double-blind, placebo-controlled trial. Metabolism Clinical and Experimental 55: 923-927, 2006.

53. Pilch PF, Thompson, P.A., Czech, M.P. Coordinate modulation of D-glucose transport activity and bilayer fluidity in plasma membranes derived from control and insulin-treated adipocytes. P Natl Acad Sci USA 77: 915-918, 1980.

54. Preuss HG, Echard, B., Perricone, N.V., Bagchi, D., Yasmin, T., Stohs, S.J. Comparing metabolic effects of six different commercial trivalent chromium compounds. Journal of Inorganic Biochemistry 102: 1986-1990, 2008.

55. Qiao W, Peng, Z, Wang, Z., Wei, J., Zhou, A. Chromium Improves Glucose Uptake and Metabolism Through Upregulating the mRNA Levels of IR, GLUT4, GS, and UCP3 in Skeletal Muscle Cells. Biol Trace Elem Res 131: 133-142, 2009.

56. Ruderman NB, Houghton, C.R.S., Hems, R. Evaluation of the isolated perfused rat hindquarter for the study of muscle metabolism. Biochem J 124: 639-651, 1971.

57. Ryan GJ, Wanko, N.S., Redman, A.R., Cook, C.B. Chromium as adjunctive treatment for type 2 diabetes. The Annals of Pharmacotherapy 37: 876-885, 2003.

58. Sakamoto K, Holman, G.D. Emerging role for AS160/TBC1D4 and TBC1D1 in the regulation of GLUT4 traffic. Am J Physiol Endocrinol Metab 295: E29-E37, 2008.

59. Schwarz K, Mertz, W. Chromium (III) and the glucose tolerance factor. Archives of Biochemistry and Biophysics 85: 292-295, 1959. 
60. Stiffler JS, Law, J.S., Polansky, M.M., Bhathena, S.J., Anderson, R.A. Chromium imporves insulin response to glucose in rats. Metabolism 44: 1314-1320, 1995.

61. Stiffler JS, Polansky, M.M., Anderson, R.A. Dietary chromium decreases insulin resistance in rats fed a high-fat, mineral-imbalanced diet. Metabolism 47: 396400, 1998.

62. Stockli J, Davey, J.R., Hohnen-Behrens, C., Xu, A., James, D.E., and Ramm, G. Regulation of glucose transporter 4 translocation by the Rab guanosine triphosphatase-activation protein AS160/TBC1D4: Role of phosphorylation and membrane association. Molecular Endrocrinology 22: 2703-2715, 2008.

63. Striffler JS, Polansky, M.M., Anderson, R.A. Overproduction of insulin in the chromium-deficient rat. Metabolism 1999.

64. Turner RC, Cull, C.A., Frighi, V., Holman, R.R. Glycemic control with diet, Sulfonylurea, Metformin or insulin in patients with type 2 diabetes mellitus: Progressive requirement for multiple therapies (UKPDS 49). JAMA 281: 2005-2012, 1999.

65. Via M, Scurlock, C., Raikhelkar, J., Di Luozzo, G., Mechanick, J. Chromium infusion reverses extreme insulin resistance in a cardiothoracic ICU patient. Nutr Clin Pract 23: 325-328, 2008.

66. Vincent JB. Chromium: celebrating 50 years as an essential element? Dalton Trans 39: 3787-3794, 2010.

67. Vincent JB. Mechanisms of chromium action: low-molecular-weight chromiumbinding substance. Journal of the American College of Nutrition 18: 6-12, 1999.

68. Wang H, Kruszewski, A., Brautigan, D.L. Cellular chromium enhances activation of insulin receptor kinase. Biochemistry 44: 8167-8175, 2005.

69. Weber H. Long-term study of the distribution of soluble chromate-51 in the rat after a single intratracheal administration. J Toxicol Environ Health 11: 749-764, 1983.

70. Wilson BE, Gondy, A. Effects of chromium supplementation on fasting insulin levels and lipid parameters in healthy, non-obese young subjects. Diabetes Research and Clinical Practice 28: 179-184, 1995.

71. Wojtaszewski JP, Jakobsen, A.B., Ploug, T., Richter, E.A. Perfused rat hindlimb is suitable for skeletal muscle glucose transport measurments. Am J Physiol Endocrinol Metab 274: 184-191, 1998.

72. Yang XP, Palanichamy, K., Ontko, A.C., Rao, M.N.A., Fang, C.X., Ren, J., Sreejayan, N. A newly synthetic chromium complex - chromium (phenylalanine)3 improves insulin responsiveness and reduces whole body glucose tolerance. Febs Lett 579: 1458-1464, 2005.

73. Young LH. AMP-Activated Protein Kinase Conducts the Ischemic Stress Response Orchestra. Circulation 117: 832-840, 2008.

74. Z Zhao P, Wang, J., Ma, H., Xiao, Y., He, L., Tong, C., Wang, Z., Zheng, Q., Dolence, E.K., Nair, S., Ren, J., Li, J. A newly synthetic chromium complexChromium (D-phenylalanine)3 activates AMP-activated protein kinase and stimulates glucose transport. Biochemical Pharmacology 77: 1002-1010, 2009. 
75. Zimmet P, Albert, K. G. M. M., Shaw, J. Global and societal implications of the diabetes epidemic. Nature 414: 782-787, 2001. 


\section{Vita}

Phillip Doerner was born in Oklahoma City, OK on November 9, 1984 to Phillip Doerner Jr. M.D. and Marsha Doerner. After graduating from Heritage Hall High School in Oklahoma City in 2003, he attended Stanford University in Stanford, California. At Stanford, he was a member of the varsity wrestling team, serving as a team captain his senior year. After graduating with a Bachelor of Arts in Human Biology in June 2008, he entered The Graduate School at The University of Texas at Austin in August 2008.

$\begin{array}{ll}\text { Permanent address : } & 4512 \text { Blackberry Run } \\ & \text { Oklahoma City, OK } 73112\end{array}$

This thesis was typed by the author. 